\title{
Time-resolved structured illumination microscopy reveals key principles of Xist RNA spreading
}

Authors: Lisa Rodermund ${ }^{1}$, Heather Coker $^{1}$, Roel Oldenkamp ${ }^{1} \dagger$, Guifeng Wei ${ }^{1}$, Joseph Bowness ${ }^{1}$, Bramman Rajkumar ${ }^{1}$, Tatyana Nesterova ${ }^{1}$, David Miguel Susano Pinto ${ }^{1}$, Lothar Schermelleh $^{1 *}$, Neil Brockdorff ${ }^{1 *}$

\author{
Affiliations: \\ ${ }^{1}$ Department of Biochemistry, University of Oxford, South Parks Road, Oxford, OX1 3QU, UK \\ $\uparrow$ Current address: Division of Gene Regulation, Netherlands Cancer Institute, Plesmanlaan 121, \\ Amsterdam, 1066 CX, Netherlands \\ 10 *Corresponding author. Email: neil.brockdorff@ bioch.ox.ac.uk (N.B.); \\ lothar.schermelleh@bioch.ox.ac.uk (L.S.)
}

\begin{abstract}
Xist RNA directs the process of X-chromosome inactivation in mammals by spreading in cis along the chromosome from which it is transcribed and recruiting chromatin modifiers to silence gene transcription. To elucidate mechanisms of Xist RNA cis-confinement, we established a sequential dual-color labeling, super-resolution imaging approach to trace individual Xist RNA molecules over time, enabling us to define fundamental parameters of spreading. We demonstrate a feedback mechanism linking Xist RNA synthesis and degradation, and an unexpected physical coupling between preceding and newly synthesized Xist RNA

20 molecules. Additionally, we find that the protein SPEN, a key factor for Xist-mediated genesilencing, has a distinct function in Xist RNA localization, stability and coupling behavior. Our results provide important insights towards understanding the unique dynamic properties of Xist RNA.
\end{abstract}

One Sentence Summary: Visualizing Xist RNA dynamics in single cells during X chromosome inactivation

\section{Main Text:}

$\mathrm{X}$ chromosome inactivation $(\mathrm{XCI})$ is the mechanism that evolved in mammals to equalize levels of X-linked gene expression in XX females relative to XY males [reviewed in (1)]. The XCI process is controlled by a $17 \mathrm{~kb}$ long non-coding RNA, Xist (X inactive specific transcript) that functions in cis to silence the chromosome from which it is transcribed. Xist RNA localizes in cis across the length of the inactive $\mathrm{X}$ chromosome (Xi) elect, recruiting silencing factors that mediate chromatin modification and transcriptional inactivation of underlying genes [reviewed in (2)]. Xist transgenes expressed from ectopic autosomal locations recapitulate Xist RNA functions, including chromosome silencing in cis $(3,4)$.

A key challenge in $\mathrm{X}$ inactivation research is to understand the basis for cis-limited localization of Xist RNA. Early studies revealed that Xist RNA concentrates over chromosomal regions that have a high gene density (5), and that Xist RNA interacts tightly with the biochemically insoluble nuclear matrix fraction (6). Consistent with the latter observation, the nuclear matrix 40 proteins hnRNPU and CIZ1 are required to anchor Xist RNA to the Xi territory (7-10). Related 
to these findings, super-resolution three-dimensional structured illumination microscopy (3D-SIM) imaging has revealed that Xist RNA molecules reside in distinct foci adjacent to hnRNPU in interchromatin channels that pervade the Xi territory (11). More recently, mapping of chromatin sites associated with Xist RNA using RNA antisense purification sequencing (RAP-seq) (12), has revealed initial preferred localization to regions that are in close 3D proximity to the site of transcription, with subsequent spreading across the chromosome (13). These findings support that preferred chromatin sites for Xist RNA association are not defined by underlying DNA sequence.

Despite the aforementioned progress, our understanding of cis-limited localization of Xist RNA remains rudimentary. We recently proposed a model that invokes that the range over which Xist RNA spreads is a function of Xist RNA abundance, based on synthesis and degradation rates, and the dynamics of the anchoring interaction of Xist ribonucleoprotein particles (RNPs) with the insoluble nuclear matrix fraction (14). To test this hypothesis, we set out to quantify the dynamic behavior of Xist molecules. Previous studies have described approaches to fluorescently tag Xist RNA in living cells using fluorescent proteins $(15,16)$, but these systems are amenable only to conventional diffraction-limited fluorescence microscopy, meaning it is not possible to observe individual Xist molecules. To overcome this limitation, we developed a novel methodology, RNA-SPLIT ( $\underline{\text { Sequential }}$ Pulse Localization Imaging over Time), that allows measurement of the dynamics and localization of Xist molecules using super-resolution 3D-SIM. We use this approach to define critical parameters underpinning the behavior of Xist molecules, and to show a novel role for the silencing protein SPEN in Xist RNA behavior.

\section{Development of RNA-SPLIT to analyze Xist RNA dynamics}

We set out to measure the dynamic behavior of individual Xist RNA molecules using superresolution 3D-SIM. The Bgl-stem-loop system (17) was employed for efficient labelling of inducible Xist RNA from its natural location on the $\mathrm{X}$ chromosome (Chr X) in XX female mouse embryonic stem cells (mESCs), or from an autosomal Xist transgene integration site on chromosome 15 (Chr 15) in XY male mESCs (Fig. 1A). The array of 18 Bgl-stem-loops was inserted at the 3' end of Xist just after exon 7 (Fig. 1A). The Bgl-stem-loops are tightly bound by the BglG protein, which was fused to a HaloTag in this instance (Fig. 1A). The use of HaloTag technology allowed for an increase in photostability and brightness sufficient for the application of 3D-SIM optical sectioning, enabling the detection of distinct focal Xist signals within subnuclear regions in 3D space, referred to henceforth as Xist territories (Fig. 1B, movie S1). The intensity of fluorescent spots within Xist territories is $\sim 3$-fold higher than unbound BglG-Halo signal in the nucleoplasm (fig. S1A). Insertion of the Bgl-stem-loop array had no effect on Xistmediated silencing, as determined using allelic chromatin RNA sequencing (ChrRNA-seq) (fig. $\mathrm{S} 1 \mathrm{~B})$. Moreover, tagged Xist RNA was shown to recruit the known co-factor CIZ1, and to establish Xi-specific histone modifications (fig. S1C). Similar results were obtained for mESCs expressing the Chr 15 Xist transgene (fig. S1, D and E). Both cell lines showed clear Xist territories in over $80 \%$ of cells $24 \mathrm{~h}$ after doxycycline induction, and there was little to no detectable promoter leakiness (fig. S1F).

We identified a time window from $1.5 \mathrm{~h}$ until $5 \mathrm{~h}$ post-induction during which we could quantify a gradual increase in the number of focal signals within the volume of the Xist territory (Fig. 1, C and D), referred to henceforth as expansion phase. A later timepoint ( $24 \mathrm{~h}$ ) was taken as 
representative of Xist RNA behavior at steady state. The number of individual foci that we observed at $5 \mathrm{~h}$ post-induction closely correlates with recent estimates for the number of Xist RNA molecules, 50-200 per cell $(10,11,18)$, indicating that each focal BglG-Halo signal corresponds to a single Xist RNA molecule. Further support for this conclusion is a striking pairwise co-localization of BglG-Halo foci and CIZ1 foci, the latter corresponding to CIZ1 protein bound to the Xist E-repeat, located immediately upstream of the Bgl stem-loop array (fig. S2AD).

We applied 3D-SIM live cell imaging to detect distinct Xist foci over a period of 5 min, using the fastest achievable frame rate (1 per $10 \mathrm{~s})$ and found that the foci were largely static. A representative experiment is shown in fig. S2E, movie S2. One possibility is that translocation of Xist molecules from their site of transcription to relatively static binding sites is too rapid to capture with a frame rate of 1 per $10 \mathrm{sec}$. To address this possibility, we attempted single-particle tracking after photoactivation (PALM-SPT), but this was unsuccessful because it is not possible to discriminate RNA bound and unbound BglG-Halo fusion protein. Live cell 3D-SIM imaging using slower frame rates was also not possible due to the extended motion of ES cells growing in colonies. To overcome this latter limitation, we developed RNA-SPLIT, in which successive rounds of labelling with different HaloTag ligands performed in live cells allowed separate imaging of the first and the subsequent round of Xist RNA synthesis (henceforth referred to as pre-synthesized and newly synthesized Xist RNA, respectively), analyzed with super-resolution 3D-SIM after formaldehyde fixation (Fig. 1, E and F). Exchange of the different BglG-ligand pairs on a single Xist molecule was found to be negligible (see experiments described below and supplementary text). Accordingly, varying labelling times in combination with a custom image processing and quantitative analysis pipeline enabled measurement of various aspects of RNA dynamics and localization, notably density, spreading behavior, RNA turnover and transcription dynamics (Fig. 1E and fig. S3, A and B).

\section{Chromosome context and rate of transcription modulate Xist RNA stability}

We applied the RNA-SPLIT protocol to assess Xist RNA turnover following induction during expansion phase (after $1.5 \mathrm{~h}$ ) or steady state (after $24 \mathrm{~h}$ ), both on Chr X and Chr 15. A gradual reduction of pre-synthesized RNA was observed over a $4 \mathrm{~h}$ time course, with higher stability seen for Chr X compared to Chr 15 expressed Xist RNA (Fig. 2A-C). In both cell lines, stability was higher in steady state compared to expansion phases. The latter observation indicates that in addition to chromosome context effects, Xist RNA stability increases with XCI progression. We noted that turnover of pre-synthesized RNA is more evident towards the periphery of Xist territories (Fig. 2B). Results for Xist RNA turnover rates were validated using a different method, SLAM-seq (19) (Fig. 2D and fig. S4, A-C). SLAM-seq analysis further allowed us to ascertain that insertion of the Bgl-stem-loop array does not significantly alter Xist transcript stability (fig. S4, A-C, and see supplementary text).

Quantitation of the average number of Xist molecules in cells indicated a general decrease from expansion to steady state phase (fig. S4D), apparently at odds with the observed increase in stability. Further analysis revealed that this is accounted for by significantly elevated Xist transcription in expansion compared with steady state, as determined using RNA-SPLIT analysis of both Chr X and Chr 15 expressed Xist RNA (Fig. 2, E and F, and fig. S4E). We noted increased transcription of Xist expressed in the Chr 15 compared to Chr X context. These 
observations suggest that the abundance of Xist RNA may be regulated by a feedback mechanism that balances rates of synthesis and degradation.

A previous study reported increased Xist RNA stability following inhibition of transcription by actinomycin D (15), also pointing to a link between Xist RNA synthesis and turnover. As actinomycin D treatment can lead to confounding indirect effects, we re-examined this finding, using doxycycline washout in preference to terminate Xist expression. Doxycycline washout performed $1.5 \mathrm{~h}$ post-induction (fig. $\mathrm{S} 4, \mathrm{~F}$ and $\mathrm{G}$ ) resulted in a dramatic increase in Xist RNA stability (Fig. 2G). This result further supports the existence of a promoter-independent feedback mechanism that links rates of Xist RNA transcription and turnover.

\section{Time-resolved analysis of Xist RNA localization}

We applied RNA-SPLIT to obtain temporally resolved 3D localization information at the level of individual Xist molecules in single cells. The site of Xist transcription was approximated based on the density and fluorescence intensity of newly synthesized Xist RNA signal. Using this approach, we found that the transcription site is on average located centrally within Xist territories in expansion phase and slightly more peripherally at steady state (fig. S5, A and B). More specifically, approximately $60 \%$ of estimated transcription sites were found in the inner zones during expansion (fig. S5B). In steady state this was significantly reduced to $40 \%$, with $\sim 60 \%$ of the transcription sites now found in the outer zone (fig. S5B). We went on to measure $3 \mathrm{D}$ distances of newly synthesized and pre-synthesized Xist RNA molecules from the transcription site (Fig. 3A). By dividing the Xist territory into three concentric zones, we were able to quantify the relative distribution of Xist molecules with respect to distance from the transcription site over time (Fig. 3B). This analysis revealed that newly synthesized but not presynthesized Xist molecules spread in 3D from the transcription site towards the periphery of the Xist territory over a $1 \mathrm{~h}$ time course during expansion phase. We calculated the average expansion rate to be $\sim 8 \mu \mathrm{m}^{3} / \mathrm{h}$. Taking into account Xist RAP-seq data collected over a similar time course (13), and also H2AK119ub1 ChIP-seq analysis shown below, we infer that the observed spreading reflects Xist molecules being transported initially to sites in close proximity to the Xist locus (see also discussion). 3D spread was not measurable using the same time course during steady state (Fig. 3B). Possible explanations include differences in Xist RNA turnover/transcription, or a more stochastic spread of Xist RNA as was proposed previously based on RAP-seq and CHART-seq experiments performed at later post-induction time points $(13,20)$.

Interestingly, RNA-SPLIT analysis revealed the frequent occurrence of pairwise association of pre-synthesized and newly synthesized Xist molecules (Fig. 3C, left panel), which we refer to as coupling. This phenomenon was also seen in experiments combining Xist RNA FISH with HaloTag staining, where HaloTag couplets are often observed over larger Xist RNA FISH foci (Fig. 3C, right panel).

We used nearest neighbor analysis (NNA) of 3D-SIM RNA-SPLIT images to quantify Xist RNP coupling at expansion and steady state in both $\mathrm{Chr}$ X and Chr $15 \mathrm{mESCs}$. Estimated median distances were in the range 160-180 nm (Fig. 3D and fig. S6A). To determine the technical offset for colocalizing nuclear focal signals, we used 5-ethynyl-2'-deoxyuridine (EdU) pulse replication labelled cells that were simultaneously detected with two colors (21). Taking into account the minimum resolvable separation using 3D-SIM of $\sim 60 \mathrm{~nm}$ obtained for the NNA of 
the dual-color EdU control sample (Fig. 3D), and an estimated diameter of Xist molecules of 50 $\mathrm{nm}$ (derived from the ratio of Xist RNA and rRNA length and the known size of a ribosome), these observations demonstrate very close spatial association of individual pre-synthesized and newly synthesized Xist molecules. This finding is further emphasized by comparison with a randomized NNA control (Fig. 3D and fig. S6A). Importantly, there is no equivalent frequency of coupling of pre-synthesized with pre-synthesized, or newly synthesized with newly synthesized Xist molecules, indicating that Xist molecules are not synthesized/transported as couplets but rather come together at distant bound sites.

To rule out that the coupling effect is caused by binding of individual Xist molecules with the different HaloTag ligands, we performed a simultaneous dual-color labelling (fig. S6B). In this case, the majority of individual Xist molecules were either labelled with one or the other color (likely due to a limitation in both Halo-tag labelling efficiency and capacity of stem loop binding). A minority of foci showed precisely co-localizing signal for the two ligands. This is distinct from the coupling observed in RNA SPLIT where the two signals are spatially associated but separate. Accordingly, the distribution of measured NNA distances in the dual labelling experiment is strikingly different from that seen in RNA-SPLIT (fig. S6B and see supplementary text).

\section{Application of RNA-SPLIT to investigate the role of CIZ1 in Xist RNA behavior}

To gain further insight into the mechanistic aspects of Xist RNA behavior we applied RNASPLIT while perturbing factors known to be involved in cis-limited Xist RNA localization. Firstly, we generated a knockout (KO) of the gene encoding CIZ1 (fig. S7, A-D), a protein associated with the insoluble nuclear matrix fraction which interacts with Xist RNA and plays a pivotal role in anchoring Xist molecules in somatic cells $(9,10)$. In line with previous analyses $(9,10)$, we observed little or no effects on Xist RNA localization in undifferentiated mESCs (Fig. S7E and fig. S7F). Accordingly, Xist transcript stability, transcription dynamics and coupling were largely unaffected and moreover, Xist-mediated silencing determined using ChrRNA-seq was unaltered (fig. S8, A-E). In marked contrast, in differentiated neural precursor cells (NPCs) derived from the Cizl KO mESCs we observed a dramatic dispersal of Xist molecules throughout the entire nucleus (Fig. 4, A and B). We quantified the localization defect in NPCs by comparing inter-molecule distances in Cizl KO and WT NPCs (Fig. 4C). In WT NPCs the density of Xist molecules increased (decreased distance between molecules) as differentiation progressed, whilst in Cizl KO NPCs density decreased (Fig. 4C).

Despite the observed delocalization of Xist RNA, ChrRNA-seq analysis demonstrated that there was no major difference in transcriptional silencing of the Xi (fig. S9A), consistent with the fact that Cizl KO female mice are viable (9). Both RNA-SPLIT analysis and ChrRNA-seq demonstrated an increased Xist RNA molecule count in NPCs as compared to mESCs, with an even more dramatic increase in Cizl KO NPCs (fig. S9, B and C). Further analysis by RNASPLIT revealed that this is linked to increased Xist transcription, most notably in Cizl KO NPCs (fig. S9D). Additionally, Xist RNA stability is increased in NPCs compared to mESCs (fig. S9E). These observations indicate that the feedback mechanism linking Xist transcription and turnover is disrupted in Cizl KO NPCs.

We went on to apply RNA-SPLIT to assess coupling of pre-synthesized and newly synthesized Xist molecules in NPCs. Coupling was readily observable in WT NPCs, demonstrating that the 
phenomenon is common to both undifferentiated and differentiated cell types (Fig. 4D). Strikingly, we also observed coupling in Cizl KO NPCs, despite the widespread dispersal of Xist molecules throughout the nucleus (Fig. 4E). This finding demonstrates that coupling of newly synthesized and pre-synthesized Xist molecules is independent of cis-limited localization to the $\mathrm{X}$ chromosome.

\section{A role for SPEN in Xist RNA localization}

The protein SPEN, which binds to the A-repeat region of Xist RNA via a triple RRM domain, plays a central role in Xist-mediated gene silencing $(8,17,22,23)$. Silencing activity has been linked to a C-terminal SPOC domain that interacts with the NCoR-HDAC3 co-repressor complex (24-26). In recent work we reported atypical Xist territories and reduced levels of Xist RNA resulting from SPEN loss of function (RRM deletion), and similarly following deletion of the Xist A-repeat (27). Consistent with these observations, prior work reported that the A-repeat is critical for in cis localization of a truncated Xist RNA transgene (28). To further investigate a possible role for SPEN in Xist RNA localization we engineered the SPEN RRM deletion in mESCs with endogenous inducible BglG-Halo-Xist (SPEN ${ }^{\triangle R R M}$; Fig. 5A and fig. S10A). Analysis by ChrRNA-seq confirmed a major silencing defect, (Fig. S10B), consistent with prior studies (26,27). 3D-SIM combined with HaloTag staining revealed a visible defect in Xist RNA localization, both in expansion and steady state phases (Fig. 5B). This defect was also visible using Xist RNA FISH analysis and widefield microscopy (fig. S10C).

Prior studies have determined a close correlation of Xist-dependent Polycomb histone modifications and Xist RNA binding as determined by RAP (13), and we therefore carried out ChIP-seq analysis of Polycomb-mediated H2AK119ub1 to approximate the chromosomal distribution of Xist RNA in SPEN ${ }^{\triangle R R M}$ mESCs. After induction of Xist for $3 \mathrm{~h}$ or $24 \mathrm{~h}$, representing expansion and steady state respectively, we observed a marked reduction in H2AK119ub1, in particular at sites further away from the Xist locus (Fig. 5C and fig. S10D). This observation indicates that SPEN is important for the long-range spread of Xist RNA.

Aberrant Xist RNA localization in $\operatorname{SPEN}^{\triangle \mathrm{RRM}} \mathrm{mESCs}$ may be a consequence of abrogated gene silencing, or alternatively may represent a distinct function of SPEN. To discriminate these possibilities, we generated mESCs with mutations in the SPOC domain (SPEN ${ }^{\text {SPOCmut }}$ ) previously shown to disrupt interaction with the NCoR/HDAC3 co-repressor (29) (Fig. 5A). ChrRNA-seq analysis revealed that mutation of the SPEN SPOC domain abrogates Xistmediated gene silencing, but to a lesser degree compared with the SPEN RRM deletion (fig. $\mathrm{S} 10 \mathrm{~B})$. This observation is consistent with a recent study that analyzed a SPOC domain deletion mutant (26). Interestingly, aberrant localization of Xist RNA was less apparent in the SPEN $^{\text {SPOCmut }} \mathrm{mESCs}$ than in the SPEN ${ }^{\triangle \mathrm{RRM}} \mathrm{mESCs}$, specifically during steady state (Fig. 5B), and moreover, there was little or no effect on Xist RNA distribution as assessed by ChIP-seq analysis of H2AK119ub1 (Fig. 5C and fig. S10D). These observations suggest a SPOC independent function of SPEN in X inactivation that is linked to a role in Xist RNA localization.

\section{SPEN modulates Xist RNA dynamics and is required for coupling Xist molecules}

We went on to quantify the effect of SPEN mutations on Xist RNA behavior. The SPEN RRM deletion (and to a lesser extent mutation of the SPOC domain), resulted in a small decrease in the 
efficiency of Xist RNA induction (Fig. S10C). While the density of Xist molecules was significantly decreased in both cell lines, the volume of spread was more affected in the SPEN RRM deletion (Fig. 6A and fig. S11A). Here, Xist occupied on average $70 \%$ of the nucleus in contrast to around $15 \%$ in the WT (Fig. 6B). The SPEN RRM deletion (but not the SPOC domain mutant) leads to reduced levels of Xist RNA at steady state (fig. S11, B and C). This finding was not attributable to decreased Xist transcription, which was actually significantly increased both in expansion and steady state (Fig. 6C and fig. S11D), but rather to a significant decrease in Xist RNA stability (Fig. 6D).

In a final series of experiments, we applied RNA-SPLIT to determine if SPEN mutations affect Xist RNP coupling. While mutation of the SPOC domain had no apparent effect, deletion of the SPEN RRM significantly impaired coupling (Fig. 6, E and F, and fig. S11, E and F). Loss of coupling was evident both in expansion and steady state phases, although most dramatically in the latter. Together these results demonstrate a previously unappreciated role for SPEN in Xist RNA behavior that is independent of gene-silencing functions mediated by the SPOC domain, and likely involves regulation of the stability of Xist molecules, localization and/or coupling.

\section{Discussion}

In this work we identify two novel parameters that need to be considered in modelling Xist RNA behavior. First, we find that the abundance of Xist molecules during expansion and steady state is maintained by a feedback mechanism that links rates of synthesis and degradation. Factors regulating the native Xist promoter are unlikely to be involved as our experiments analyzed Xist RNA expressed from the heterotypic doxycycline promoter. The feedback mechanism is unaffected by mutation of the SPEN SPOC domain, indicating that it does not require Xistmediated gene silencing, but is perturbed upon SPEN RRM deletion, and in Cizl KO NPCs. Accordingly, we suggest that anchoring of Xist molecules to proteins of the biochemically insoluble nuclear matrix fraction, which is perturbed in the absence of the SPEN RRM domain in mESCs and Cizl KO NPCs, may be important for linking rates of transcription and turnover. Second, we find a remarkable spatial co-localization of individual newly synthesized with presynthesized Xist molecules that we refer to as coupling. The spatial and temporal information we obtained indicates that coupling takes place at sites bound by Xist molecules rather than at the Xist transcription site. We speculate that a conformational switch occurs when Xist molecules anchor at destination sites, and that this facilitates coupling, either with a mobile/diffusing Xist molecule, or a second anchored Xist molecule located at a different site, but brought into proximity by elastic motion of mesoscale chromatin domains that subdivide the chromosome (30) (fig. S12, A and B).

Experiments to directly visualize the dynamic movement of single Xist molecules using live-cell 3D-SIM revealed a relatively static behavior, albeit subject to the limitations of the slow frame rate intrinsic to 3D-SIM imaging and the cell movements that occur using this experimental system. A similarly static behavior was observed in a recent study that used an alternative strategy for fluorescent labelling of Xist molecules for 3D-SIM imaging (18). This study additionally provided evidence that the static foci represent preferred anchor sites occupied by 50-100 Xist molecules in each cell. Regardless, it remains incontrovertible that Xist molecules must undergo dynamic movements to achieve their distribution across the chromosome. Using RNA-SPLIT we determined that during the expansion phase, Xist territories enlarge radially at a 
rate of $\sim 8 \mu \mathrm{m}^{3} / \mathrm{h}$. The behavior that we observe is consistent with the proposal that Xist molecules initially translocate to anchor sites that are proximal in 3D, before being distributed more widely $(13,20)$. The fact that we see a relatively homogeneous and widespread distribution of the pre-synthesized Xist molecules during expansion, together with the observation that turnover appears to occur preferentially at the periphery of Xist territories, suggests individual Xist molecules translocate and couple at successive anchor sites in a series of 'jumps' (fig. S12 C). Although the basis for translocation of Xist molecules away from the Xist transcription site is unknown, we recently proposed that this could be attributable to fast diffusion of Xist molecules or to direct transfer through chromatin domain movements bringing preferred anchor sites and the Xist transcription site into direct contact; the Velcro ball model (14). Further investigation of this aspect of Xist RNA behavior will require the development of approaches that enable individual Xist molecules to be tracked continually with a fast frame rate and/or over longer periods.

Our results demonstrate a key role for the silencing protein SPEN in long-range spreading of Xist RNA towards the chromosome termini. This novel function is independent of SPOC domain-mediated silencing activity, and hence provides an explanation for differences observed previously comparing SPEN null and SPOC domain mutant mESCs (26). Deletion of the Xist Arepeat, with which SPEN interacts, also results in disrupted spread of Xist RNA during expansion phase, as determined by RAP-seq analysis (13), and we suggest that this too is linked to the role of SPEN in Xist localization. An interesting possibility is that the SPOC-independent function of SPEN is important for transferring Xist RNA from initial 3D proximal sites to other locations on the chromosome. Although the underlying molecular mechanism for SPEN affecting Xist localization is unknown, our analysis of different mutations suggests a link to the abundance of Xist molecules and/or coupling. Further unravelling of this mechanism presents an important goal for future studies.

\section{Materials and Methods}

\section{Generation of cell lines}

30 Tissue culture. Mouse embryonic stem cells (mESCs) were grown in Dulbecco's modified Eagle's medium (DMEM; Life Technologies) supplemented with $10 \%$ fetal calf serum (Seralab), $0.1 \mathrm{mM}$ non-essential amino acids, $2 \mathrm{mM}$ L-glutamine, $50 \mu \mathrm{M} \beta$-mercaptoethanol and $100 \mathrm{U} / \mathrm{mL}$ penicillin / $100 \mu \mathrm{g} / \mathrm{mL}$ streptomycin (Life Technologies), as well as $1000 \mathrm{U} / \mathrm{mL} \mathrm{LIF}$ (made in-house), on gelatin-coated plates with feeder cells, which were generated by inactivation of mouse fibroblasts with Mitomycin $\mathrm{C}$ (Sigma-Aldrich), at $37^{\circ} \mathrm{C}$ with $5 \% \mathrm{CO}_{2}$ in a humid atmosphere. ES cells were passaged after treatment with TrypLE Express (Thermo Fisher Scientific) every 2-3 days. Before transfection, cells were grown on gelatin-coated 6-well plates with feeders.

WT mouse ES cell line. iXist-Chr X mESCs were used as parental cell line for the generation of the WT mESC line (27). The Bgl-stem-loop system was chosen for the labelling of Xist RNA. Due to concerns that $\mathrm{BglG}$ expression might be silenced over time, the BglG fusion protein was genetically engineered to be doxycycline inducible. Due to the superior fluorescent properties of organic dyes over fluorescent proteins and the possibility of flexible pulse labeling, a HaloTag approach was chosen for fluorescent labelling of the BglG protein for live cell and superresolution imaging ( $\underline{31}$ ). Cells were transfected with $2 \mu \mathrm{g}$ of a vector encoding for doxycycline 
inducible BglG-Halo fusion protein using Lipofectamine 2000 (Life Technologies) according to the manufacturer's instructions. Cells were then passaged to $90 \mathrm{~mm}$ gelatin-coated Petri dishes with feeders and grown in medium containing $200 \mu \mathrm{g} / \mathrm{mL}$ neomycin (Geneticin (G-418); Thermo Fisher Scientific) for 10 days. Clones were picked and genomic DNA (gDNA) was extracted, before successful insertions were screened by PCR (table S1). Selected clones were expanded and BglG-Halo expression was assessed by HaloTag ligand staining, and subsequent widefield fluorescence microscopy with an inverted fluorescence Axio Observer Z.1 microscope (Zeiss). Having selected a clone with intermediate $\mathrm{BglG}$ expression, low enough to minimize background but high enough to label all Xist molecules efficiently, a Bgl-stem-loop array was inserted within exon 7 of the Xist locus by CRISPR/Cas9 mediated genome engineering. Here, a homology construct containing homology regions $1 \mathrm{~kb} 5^{\prime}$ and $3^{\prime}$ of the targeted insertion site within exon 7 of Xist was targeted by co-transfection with a specific sgRNA (table S1), which was designed using the WGE - CRISPR design tool (Wellcome Sanger Institute) and cloned into a backbone vector encoding for the CRISPR/Cas9 protein (PX459, Addgene). Cells were transfected overnight with $2 \mu \mathrm{g}$ of the sgRNA construct and $1.15 \mu \mathrm{g}$ of the targeting construct using Lipofectamine 2000 (Life Technologies) according to the manufacturer's instructions, and then passaged to $90 \mathrm{~mm}$ gelatinized Petri dishes with feeders. Cells were grown under antibiotic selection with $1.75 \mu \mathrm{g} / \mathrm{mL}$ puromycin for $48 \mathrm{~h}$ and thereafter grown for a further 9 days before being picked. Clones with successful insertion were selected by PCR screening after gDNA extraction (table S1). Successful labelling of BglG-Halo-Xist was confirmed by HaloTag ligand staining followed by 3D-SIM. Comparison of BglG-Halo-Xist signal intensity to background signal from unbound BglG-Halo allowed for the selection of the most suitable cell line for imaging experiments.

Transgenic mouse ES cell line. XY P4D7 mESCs were used as parental cell line for the generation of the transgenic mESC line (17). A construct with doxycycline inducible Xist containing an array of $18 \mathrm{Bgl}-\mathrm{stem}-\mathrm{loops}$ within exon 7 was used (17). Additionally, cells were transfected with the construct encoding doxycycline inducible BglG-Halo protein described earlier. Cells were co-transfected overnight with $5 \mu \mathrm{g}$ of the transgenic Xist and $2.5 \mu \mathrm{g}$ of the BglG-Halo construct using TransIT-LT1 transfection reagent (Mirusbio) according to the manufacturer's instructions. Cells were then passaged to $90 \mathrm{~mm}$ gelatin-coated Petri dishes with feeders and grown in medium containing $200 \mu \mathrm{g} / \mathrm{mL}$ neomycin (Geneticin (G-418); Thermo Fisher Scientific) for 10 days. Successful insertions of the BglG-Halo sequence were screened by PCR analysis of the gDNA (table S1). Transgenic Xist expression was assessed by Xist RNA FISH and subsequent widefield fluorescence microscopy with an inverted fluorescence Axio Observer Z.1 microscope (Zeiss). BglG-Halo expression and efficient labelling of transgenic BglG-Halo-Xist was confirmed by HaloTag ligand staining and 3D-SIM. Comparison of BglGHalo-Xist signal intensity to background signal from unbound BglG-Halo allowed for the selection of the most suitable cell line for imaging experiments. ChrRNA-seq later enabled 40 determination of the insertion site of transgenic Xist on chromosome 15.

Cizl KO ES cell line. The aforementioned WT ES cell line was used as parental cell line for the generation of the Cizl $\mathrm{KO} \mathrm{mESCs}$ by CRISPR/Cas9 mediated genome engineering. Here, a sgRNA, which had been previously used to induce a frameshift mutation (10), was used in combination with a second sgRNA designed using the WGE - CRISPR design tool to achieve a genomic deletion of $10.66 \mathrm{~kb}$, resulting in the deletion of most of the Cizl gene (table $\mathrm{S} 1$ ). The 
sgRNAs were cloned into backbone vectors encoding for the CRISPR/Cas9 protein (PX459, Addgene). Cells were transfected overnight with $2 \mu \mathrm{g}$ of each sgRNA construct using Lipofectamine 2000 (Life Technologies) according to the manufacturer's instructions. Cells were then passaged to $90 \mathrm{~mm}$ gelatinized Petri dishes with feeders and grown under antibiotic selection with $2 \mu \mathrm{g} / \mathrm{mL}$ puromycin for $48 \mathrm{~h}$. Colonies were grown for 8 days before being picked. Selected clones with successful genomic deletion were screened for by PCR analysis of gDNA (table S1). Absence of CIZ1 was confirmed by Western blot and immunofluorescence staining for CIZ1, while successful labelling of BglG-Halo-Xist was confirmed by HaloTag ligand staining followed by 3D-SIM. A final clone for analysis was chosen based on the results of these assays, as well as the comparison of BglG-Halo-Xist signal intensity to background signal from unbound BglG-Halo.

$S P E N^{\triangle R R M} E S$ cell line. The aforementioned WT ES cell line was used as parental cell line for the generation of the SPEN ${ }^{\triangle R R M} \mathrm{mESCs}$ by CRISPR/Cas9 mediated genome engineering. Previously described sgRNAs (23) were used to achieve a genomic deletion of $38 \mathrm{~kb}$, resulting in the KO of RRM2-4 of Spen (table S1). Cells were transfected and successful deletion was screened for as described above for the Cizl KO cell line. SPEN RRM deletion in selected clones was confirmed by Southern blot. Presence of polyploid and XO cells was excluded by Xist RNA FISH and successful labelling of BglG-Halo-Xist was confirmed by HaloTag ligand staining followed by 3D-SIM. A final clone for analysis was chosen based on the results of these assays, as well as the comparison of BglG-Halo-Xist signal intensity to background signal from unbound BglG-Halo.

SPEN ${ }^{\text {SPOCmut }}$ ES cell line. The aforementioned WT ES cell line was used as parental cell line for the generation of the SPEN ${ }^{\text {SPOCmut }}$ mESCs by CRISPR/Cas9 mediated genome engineering. The SPOC mutant, which disrupts the interaction between SPEN and NCoR/SMRT complex (32), was achieved by amino acid substitutions R3552A and R3554A in the SPOC domain of SPEN. This substitution was previously described to abolish binding of SPEN to NCOR1 an SMRT corepressive complexes in vitro (29). The substitutions were engineered into a $0.5 \mathrm{~kb}$ homology construct corresponding to the region of SPEN exon 14. The sgRNA (table S1) was cloned into a backbone vector encoding for the CRISPR/Cas9 protein (PX459, Addgene). Cells were transfected overnight with $1.42 \mu \mathrm{g}$ of the sgRNA construct and $2.5 \mu \mathrm{g}$ of the targeting construct using Lipofectamine 2000 (Life Technologies) according to the manufacturer's instructions. Cells were then passaged to $90 \mathrm{~mm}$ gelatinized Petri dishes with feeders and grown under antibiotic selection with $3 \mu \mathrm{g} / \mathrm{mL}$ puromycin for $48 \mathrm{~h}$. Colonies were grown for 10 days before being picked. Selected clones with successful amino acid substitution were screened after gDNA extraction by NcoI digestion, PCR analysis and Sanger sequencing of the PCR fragments (table S1). Presence of polyploid and XO cells was excluded by Xist RNA FISH and successful labelling of BglG-Halo-Xist was confirmed by HaloTag ligand staining followed by 3D-SIM. Chromatin RNA sequencing (ChrRNA-seq) finally confirmed successful amino acid substitution 40 and a final clone for analysis was chosen based on the cumulative results of these assays, as well as the comparison of BglG-Halo-Xist signal intensity to background signal from unbound BglGHalo.

NPC derivation. In order to study Xist behavior in differentiated cells, WT and Ciz, $1 \mathrm{KO}$ mESCs were differentiated into neural progenitor cells (NPCs) following a following a previously adapted protocol $(33,34)$. Cells were grown in gelatin-coated T25 flasks with feeder cells. 
Feeders were removed before differentiation by pre-plating three times for $40 \mathrm{~min}$ each. Then, $0.45 \times 10^{6}$ cells and $0.55 \times 10^{6}$ cells, respectively, were plated in a gelatin-coated T25 flasks each and grown in N2B27 medium containing $1 \mu \mathrm{g} / \mathrm{mL}$ doxycycline for 7 days. On day 7 , the flasks

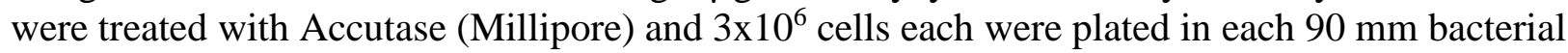
petri dishes with N2B27 medium containing $1 \mu \mathrm{g} / \mathrm{mL}$ doxycycline and $10 \mathrm{ng} / \mathrm{mL}$ EGF and FGF (Peprotech) to prevent cellular attachment. For imaging at day 10 of differentiation, cells were plated onto gelatin-coated $18 \times 18 \mathrm{~mm}$ No. $1.5 \mathrm{H}$ precision coverslips $( \pm 5 \mu \mathrm{m}$ tol.; Marienfeld Superior) at day 7 . At day 10, cell aggregates were collected by mild centrifugation, before being plated onto gelatin-coated $90 \mathrm{~mm}$ petri dishes in N2B27 medium containing $1 \mu \mathrm{g} / \mathrm{mL}$ doxycycline and $10 \mathrm{ng} / \mathrm{mL}$ EGF and FGF (Peprotech) each. When $80 \%$ confluent, cells were split 1:4 by Accutase (Millipore) treatment at room temperature followed by collection in PBS and centrifugation at 1,500 rpm for $5 \mathrm{~min}$. For HaloTag staining at day 20 of differentiation, cells were plated onto precision coverslips at day 16 of differentiation. For ChrRNA-seq at day 30 of differentiation, cells were expanded onto one $145 \mathrm{~mm}$ petri dish per replica on day 25 of differentiation.

\section{Xist RNA FISH}

Xist RNA FISH for scoring. All cells were grown on gelatin-coated $18 \times 18 \mathrm{~mm}$ No. $1.5 \mathrm{H}$ precision coverslips ( $\pm 5 \mu \mathrm{m}$ tol.; Marienfeld Superior) in a 6-well plate on a layer of feeder cells. When reaching 60-70 \% confluency, mESCs were induced for $3 \mathrm{~h}$ or $24 \mathrm{~h}$ with $1 \mu \mathrm{g} / \mathrm{mL}$ doxycycline, reserving one coverslip per experiment without doxycycline induction. After induction, coverslips were washed briefly with PBS twice, before being fixed with $3.7 \%$ formaldehyde in PBS at room temperature for $10 \mathrm{~min}$. Cells were rinsed with PBS and then permeabilized with $0.5 \%$ Triton X-100 in PBS for $10 \mathrm{~min}$ at room temperature, followed by two washes with $70 \%$ EtOH. Coverslips were then dehydrated with subsequent washes with $80 \%$, $95 \%, 100 \% \mathrm{EtOH}$ for 5 min each, and dried briefly. Each coverslip was hybridized with $15 \mu \mathrm{L}$ probe/ hybridization buffer mix. Xist probe was generated from an $18 \mathrm{~kb}$ cloned cDNA spanning the whole Xist transcript using a nick translation kit (Abbott Molecular) as previously described (17). $3 \mu \mathrm{L}$ Texas Red labelled Xist RNA FISH probe per hybridization was added to 1/3 volume $10 \mathrm{mg} / \mathrm{mL}$ salmon sperm DNA, then precipitated by addition of 1/10 volume of $3 \mathrm{M} \mathrm{NaOAc}$ and 3 volumes $100 \% \mathrm{EtOH}$. After washing with $70 \% \mathrm{EtOH}$, the pellet was dried by speed vacuum and resuspended in $6 \mu \mathrm{L}$ deionized formamide (Sigma) per hybridization. An equal amount of $2 x$ hybridization buffer (4x SSC, $20 \%$ dextran sulfate, $2 \mathrm{mg} / \mathrm{mL}$ BSA (NEB), 1/10 volume nuclease free water and $1 / 10$ volume VRC pre-warmed at $65^{\circ} \mathrm{C}$ for $5 \mathrm{~min}$ before use) was added, and the probe/ hybridization buffer mix was denatured at $75^{\circ} \mathrm{C}$ for 5 min before being chilled on ice and used for hybridization in a humid chamber overnight at $37^{\circ} \mathrm{C}$. The next day, coverslips were washed 3 times with pre-warmed $50 \%$ formamide/ $2 x \mathrm{SSC}$ at $42{ }^{\circ} \mathrm{C}$ for $5 \mathrm{~min}$ each, and subsequently 3 times with $2 x \mathrm{SSC}$ at $42{ }^{\circ} \mathrm{C}$ for 5 min each. Coverslips were mounted with 4',6diamidino-2-phenylindole (DAPI) containing Vectashield antifade mounting medium (Vector Labs) centrally on Superfrost Plus microscopy slides (VWR). Slides were dried, sealed using clear nail polish and cleaned for imaging. Imaging and scoring were carried out using an inverted fluorescence Axio Observer Z.1 microscope (Zeiss) using a PlanApo ×63/1.4 NA oil-immersion objective. Images were acquired using AxioVision software.

45 Xist RNA FISH for 3D-SIM. This protocol was adapted from the Stellaris FISH protocol (Biosearch Technologies) for a combination of Xist RNA FISH with HaloTag ligand staining of 
BglG-Halo-Xist. All cells were grown on gelatin-coated $18 \times 18 \mathrm{~mm}$ No. $1.5 \mathrm{H}$ precision coverslips in a 6-well plate on a layer of feeder cells. When reaching 60-70\% confluency, mESCs were induced for $3 \mathrm{~h}$ or $24 \mathrm{~h}$ with $1 \mu \mathrm{g} / \mathrm{mL}$ doxycycline, before being stained with HaloTag ligand. After washout of the ligand, coverslips were washed twice with PBS and fixation was carried out by adding $3 \%$ formaldehyde $(\mathrm{pH} 7)$ prepared in fresh PBS for 10 min at room temperature. A stepwise exchange of PBST (0.05\% Tween 20 PBS) was carried out, then coverslips were washed twice in PBST. Cells were permeabilized in $0.2 \%$ Triton X-100 PBS for $10 \mathrm{~min}$ at room temperature, before being washed twice with PBST. Then, coverslips were blocked in $2 \%$ BSA / $0.5 \%$ fish skin gelatin / PBST containing freshly added RNAsin Plus (Promega) at a final concentration of $2 \mathrm{U} / \mu \mathrm{L}$ for $30 \mathrm{~min}$. In the meantime, the Xist RNA FISH probe was prepared and precipitated as described before. However, after speed vacuum the probe pellet was resuspended in $12 \mu \mathrm{L}$ Stellaris Hybridization buffer (Biosearch Technologies) per hybridization instead of formamide. The probe/hybridization buffer was prepared as described above, with the exception that the $2 x$ hybridization buffer was prepared with $1 / 10$ volume formamide before being added to the probe. After blocking, the cells were washed 3 times with PBST and fixed as before. Then, the coverslips were washed twice in PBST again, followed by a wash in 2x SSC. Next, the coverslips were incubated with FISH probe/ hybridization buffer overnight at $37^{\circ} \mathrm{C}$ on parafilm in an extra humid chamber. The next day, the coverslips were transferred to a 6-well plate containing $1 \mathrm{~mL}$ wash buffer A (Biosearch Technologies) per well. After an incubation at $37^{\circ} \mathrm{C}$ for $30 \mathrm{~min}$, wash buffer A was replaced with $1 \mathrm{~mL}$ wash buffer A containing $5 \mathrm{ng} / \mathrm{mL}$ DAPI, and coverslips were incubated at $37{ }^{\circ} \mathrm{C}$ for $30 \mathrm{~min} .1 \mathrm{~mL}$ of $2 \mathrm{x} \mathrm{SSC}$ was added to each well, followed by an incubation of $5 \mathrm{~min}$ at room temperature. Finally, coverslips were mounted centrally on the unfrosted side of Superfrost Plus microscopy slides (VWR) using non-setting Vectashield antifade mounting medium (w/o DAPI), sealed with clear nail polish and imaged within a week using the DeltaVision OMX V3 Blaze system (GE Healthcare).

\section{Immunofluorescence labelling}

All cells were grown on gelatin-coated $18 \times 18 \mathrm{~mm}$ No. $1.5 \mathrm{H}$ precision coverslips in a 6 -well plate on feeder cells. When reaching 60-70 \% confluency, mESCs were induced for $3 \mathrm{~h}$ or $24 \mathrm{~h}$ with 1 $\mu \mathrm{g} / \mathrm{mL}$ doxycycline. Optionally, cells were stained with HaloTag ligand at this stage for a combination of HaloTag ligand and immunofluorescence staining. Coverslips were washed twice with PBS and fixation was carried out by adding $2 \%$ formaldehyde prepared in fresh PBS (pH 7) for 10 min at room temperature. A stepwise exchange of PBST was carried out, before coverslips were washed twice in PBS. Then, cells were permeabilized with $0.2 \%$ Triton X-100 in PBS for $10 \mathrm{~min}$ at room temperature, followed by a wash with PBST. Coverslips were blocked using $3 \% \mathrm{BSA} / 5 \%$ normal goat serum/ PBST on parafilm in a humid chamber for $30 \mathrm{~min}$ at room temperature, and then incubated with primary antibody (table S2) diluted in block buffer for $1 \mathrm{~h}$ in a humidified chamber at $37^{\circ} \mathrm{C}$. After 3 washes in PBST, coverslips were incubated 40 with the Alexa Fluor-conjugated secondary antibody (table S2) diluted 1:1000 in block buffer for $30 \mathrm{~min}$ in a humidified chamber at $37^{\circ} \mathrm{C}$. After another 4 washes with PBST, the cells were post-fixed as before, followed by a final wash in PBST. Lastly, coverslips were incubated with 2 $\mu \mathrm{g} / \mathrm{mL}$ DAPI in PBS for $10 \mathrm{~min}$, before being mounted in non-setting Vectashield medium centrally on the unfrosted side of Superfrost Plus microscopy slides (VWR), sealed with clear nail polish and imaged within a week using the DeltaVision OMX V3 Blaze system (GE Healthcare). 


\section{HaloTag staining}

All cells were grown on gelatin-coated $18 \times 18 \mathrm{~mm}$ No. $1.5 \mathrm{H}$ precision coverslips in a 6 -well plate on feeder cells. When reaching 60-70\% confluency, mESCs were induced for $3 \mathrm{~h}$ or $24 \mathrm{~h}$ with $1 \mu \mathrm{g} / \mathrm{mL}$ doxycycline. Then, cells were incubated with $50 \mathrm{nM}$ diAcFAM HaloTag ligand (488 $\mathrm{nm}$, Promega) and $1 \mu \mathrm{g} / \mathrm{mL}$ doxycycline for $45 \mathrm{~min}$, before being washed with medium containing $1 \mu \mathrm{g} / \mathrm{mL}$ doxycycline for $15 \mathrm{~min}$. After a brief wash with PBS, cells were fixed for 10 min at room temperature with $2 \%$ formaldehyde prepared fresh in PBS (pH 7). A stepwise exchange of PBST was carried out, and cells were permeabilized with $0.2 \%$ Triton X-100 for 10 min, followed by two washes with PBST. Next, cells were incubated with $2 \mu \mathrm{g} / \mathrm{mL}$ DAPI in PBST for 10 min, before being washed briefly with PBS and, subsequently with $\mathrm{ddH}_{2} \mathrm{O}$ to remove salt. Lastly, coverslips were mounted on the unfrosted side of Superfrost Plus microscopy slides (VWR) using non-setting Vectashield medium, sealed with clear nail polish and imaged within a week using the DeltaVision OMX V3 Blaze system (GE Healthcare).

\section{D-SIM}

Acquisition. 3D-SIM imaging was performed on a DeltaVision OMX V3 Blaze system (GE Healthcare) equipped with a 60x/1.42 NA Plan Apo oil immersion objective (Olympus), pco.edge $5.5 \mathrm{sCMOS}$ cameras (PCO), and 405, 488, 593 and $640 \mathrm{~nm}$ lasers. Image stacks were acquired with a z-distance of $125 \mathrm{~nm}$ and with 15 raw images per plane (5 phases, 3 angles). Spherical aberration after reconstruction was reduced by using immersion oil of different refractive indices (RIs) matched to respective optical transfer functions (OTFs). Here, immersion oil with an RI of 1.514 was used for the sample acquisition and matched to OTFs generated using immersion oil of RI 1.512 for the blue and green, and 1.514 for the red channel. OTFs were acquired using $170 \mathrm{~nm}$ diameter blue emitting PS-Speck beads and $100 \mathrm{~nm}$ diameter green and red emitting FluoSphere beads (Thermo Fisher Scientific).

Reconstruction. The raw data was computationally reconstructed with softWoRx 6.5.2 (GE Healthcare) using channel-specific OTFs and Wiener filter settings of 0.005. A lateral (x-y) resolution of approximately $120 \mathrm{~nm}$ and an axial (z) resolution of approximately $320 \mathrm{~nm}$ was achieved (30). All data underwent assessment via SIMcheck (35) to determine image quality via analysis of modulation contrast to noise ratio (MCNR), spherical aberration mismatch, reconstructed Fourier plot and reconstructed intensity histogram values. Of note, DAPI reconstructions in $\mathrm{mESC}$ were typically below the quality threshold levels of average MCNR of 5 , and were therefore only used to indicate the nuclear outlines. Reconstructed 32-bit 3D-SIM datasets were thresholded to the stack modal intensity value and converted to 16-bit composite zstacks to discard negative intensity values using SIMcheck's "threshold and 16-bit conversion" utility and MCNR maps were generated using the "raw data modulation contrast" tool of SIMcheck. To eliminate false positive signals from reconstructed noise, we applied a modulation contrast filtering using an adapted in-house Fiji script ( $\underline{36})$. Here, all pixels in the reconstructed dataset where the corresponding MCNR values in the raw data map fall below an empirically chosen threshold of 4.0 are set to zero intensity. Thereafter, the resulting 'masked' reconstructed dataset is blurred with a Gaussian filter with 0.8 pixel radius (xy) to smoothen hard edges (fig. S3B; the 'modulation contrast filter' script has meanwhile been implemented as utility with added functionalities in an updated version of SIMcheck). Widefield images were generated 
from averaging phase shifted raw 3D-SIM data of each z-position. Iterative deconvolution of widefield image stacks was performed in softWoRx using standard settings.

Alignment. Color channels were registered in 3D with the open-source software Chromagnon 0.85 (37) determining alignment parameter (x,y,z-translation, $\mathrm{x}, \mathrm{y}, \mathrm{z}$-magnification, and $\mathrm{z}$ rotation) from a 3D-SIM dataset acquired on the date of image acquisition of multicolor-detected 5-ethenyl-2'-deoxyuridine (EdU) pulse replication labelled C127 mouse cells serving as biological 3D alignment calibration sample (21).

3D-SIM live cell imaging. Cells were grown on gelatin-coated $35 \mathrm{~mm}$ No. $1.5 \mathrm{H}$ glass bottom imaging dishes (Ibidi) on feeder cells. When reaching $50 \%$ confluency, mESCs were induced for $24 \mathrm{~h}$ with $1 \mu \mathrm{g} / \mathrm{mL}$ doxycycline. Then, cells were incubated with medium containing $50 \mathrm{nM}$ JF-646 HaloTag ligand (Janelia Fluor 646, kindly provided by Luke Lavis, HHMI Janelia) and 1 $\mu \mathrm{g} / \mathrm{mL}$ doxycycline for $45 \mathrm{~min}$, before being washed with medium containing $1 \mu \mathrm{g} / \mathrm{mL}$ doxycycline for $15 \mathrm{~min}$. Before imaging, cells were washed briefly with PBS and medium was replaced with phenol red free medium with $1 \mu \mathrm{g} / \mathrm{mL}$ doxycycline. For live-cell 3D-SIM image stacks were acquired in $10 \mathrm{~s}$ intervals for up to $10 \mathrm{~min}$. Image acquisition was performed at $37{ }^{\circ} \mathrm{C}$ with $5 \% \mathrm{CO}_{2}$. To adapt for the temperature increase, immersion oil with an RI of 1.520 was used for the sample acquisition and matched to OTFs generated. Images were then processed as described above, with the exception that bleach correction was carried out.

\section{RNA-SPLIT}

Sample preparation. All cells were grown on gelatin-coated $18 \times 18 \mathrm{~mm}$ No $1.5 \mathrm{H}$ precision coverslips as described above for HaloTag staining. ES cells were induced for different times with $1 \mu \mathrm{g} / \mathrm{mL}$ doxycycline and stained with HaloTag ligands dependent on the variation of RNA-SPLIT as described below. RNA-SPLIT was determined to achieve optimal results when using the diAcFAM HaloTag ligand (Promega) as first pulse label and the JF-585 HaloTag ligand (kindly provided by Luke Lavis, HHMI Janelia) as second pulse label. Initial experiments with different dye concentrations showed that a concentration of $50 \mathrm{nM}$ for each of the ligands yielded optimal results. After a wash with PBS, samples were fixed and mounted as described above.

Nascent Xist RNA dynamics. For assessing the transcription dynamics of Xist RNA, cells grown on precision coverslips were sequentially stained with two different HaloTag ligands in each experiment. For analysis of expansion or steady state phase, cells were induced for either $1.5 \mathrm{~h}$ or $24 \mathrm{~h}$ with $1 \mu \mathrm{g} / \mathrm{mL}$ doxycycline, respectively. Then, cells were incubated with $50 \mathrm{nM}$ diAcFAM HaloTag ligand (488 nm, Promega) and $1 \mu \mathrm{g} / \mathrm{mL}$ doxycycline for $45 \mathrm{~min}$ to label presynthesized Xist RNA molecules, before washing with medium containing $1 \mu \mathrm{g} / \mathrm{mL}$ doxycycline for $15 \mathrm{~min}$. Next, the different coverslips were incubated with $50 \mathrm{nM}$ JF-585 HaloTag ligand and $1 \mu \mathrm{g} / \mathrm{mL}$ doxycycline for 10, 20,30, 40,50 and $60 \mathrm{~min}$ respectively to label newly synthesized Xist RNA molecules, before being washed with PBS. Induction and staining times with the first HaloTag ligand were staggered, such that all coverslips could be fixed at the same time despite the different staining times with the second HaloTag ligand.

Xist turnover on chromatin. For assessing the turnover of Xist RNA, cells grown on precision coverslips were stained with $50 \mathrm{nM}$ diAcFAM HaloTag ligand after $1.5 \mathrm{~h}$ or $24 \mathrm{~h}$ doxycycline 
induction, respectively, as described above. After the first pulse, coverslips were incubated with $50 \mathrm{nM}$ JF-585 HaloTag ligand and $1 \mu \mathrm{g} / \mathrm{mL}$ doxycycline for 60, 80, 100, 120, 140, 160, 180, 200 and 220 min respectively to label newly synthesized Xist RNA molecules, while one coverslip per experiment was not stained with the second HaloTag ligand at all and served as 0 min time point. Coverslips were finally washed with PBS. Induction and staining times with the first HaloTag ligand were staggered, such that all coverslips could be fixed at the same time despite the different staining times with the second HaloTag ligand. For each experiment, the endpoint was determined as when signal from the first HaloTag ligand could no longer be detected in the cells for two timepoints in a row.

Image analysis workflow. Reconstructed 3D-SIM image stacks were pre-processed and subjected to modulation contrast filtering as described above ( $\underline{36})$. Thereafter, conservative manual thresholding of the red and green channel was performed in order to discard background signal originating from free diffusing fluorescent $\mathrm{BglG}-\mathrm{Halo}$ and thus prevent detection of falsepositive signals. Lateral color channel alignment was performed as described above. The resulting images were used as representative images of whole nuclei. For further analysis however, the DAPI channel was discarded, and Xist territories were cropped manually using Fiji to exclude signal from BglG-Halo accumulation in the nucleoli, or signal from other cells. The cropped dimensions were later used to define Xist territory volume during expansion and steady state in all different cell types.

In order to assess the difference in fluorescence intensity originating from the Xist territory as compared to the BglG-Halo fusion protein in nucleoplasm, we determined the intensity fold change of the average fluorescence signal intensity of segmented foci (using the makefile script described below for the determination of centroid positions) within the cropped Xist territory as compared to segmented background foci in a same sized nuclear volume outside the Xist territory $(\underline{36})$. For this analysis manual thresholding was not performed so as to capture fluorescence background foci from free BglG fusion proteins. Similarly, we assessed how many CIZ1 molecules bind to each Xist molecule by measuring the average fluorescence intensity of the CIZ1 immunofluorescence foci within the Xist territory and in a corresponding volume of the nucleus outside the Xist territory.

The processed RNA-SPLIT image files were analyzed using an in-house adapted makefile script for masking of the signal and centroid determination by watershed algorithm, which also allowed for the determination and comparison of the intensities of different Xist foci $(\underline{36})$. The output data was used to determine the number of Xist foci during expansion and steady state phase in all different cell types. Moreover, it was used to determine the transcription rates based on the centroid count of the HaloTag ligand labelling newly synthesized Xist RNA molecules, as well as the turnover of Xist RNA based on the count of the HaloTag ligand labelling pre-synthesized Xist RNA molecules.

Nearest neighbor analysis (NNA) and variations thereof were conducted based on the $\mathrm{x}, \mathrm{y}$ 40 and $\mathrm{z}$ coordinates of centroids determined previously using a different in-house adapted makefile script ( $\underline{36})$. Distances determined from HaloTag ligand labelling newly synthesized RNA to the HaloTag ligand labelling pre-synthesized RNA were used to assess pairing behavior of Xist RNA during expansion and steady state in all cell types. Data from female C127 cells pulsed with EdU used previously for alignment was used as a technical control to determine nearest 45 neighbor distances of molecules labelled with different ligands at the same time. Here, only EdU files acquired on the days of corresponding RNA-SPLIT data acquisition were used, allowing for 
sample-specific matched technical controls. Additionally, 'Random' sample controls were generated in a sample-specific manner by scrambling of the $\mathrm{x}, \mathrm{y}$ and $\mathrm{z}$ coordinates of the centroids determined for newly synthesized RNA of each specific sample using Microsoft Excel.

Using a variation of the aforementioned NNA, median distances between each molecule and its ten nearest neighboring molecules in the same channel were determined as a measure of Xist RNA density. Combined densities of newly synthesized and pre-synthesized RNA in expansion and steady state were used for comparison of Xist RNA densities in different cell types. For NPCs in particular, median distances between each molecule and all other molecules were determined as measure of Xist RNA density in order to account for widespread distribution of Xist RNA throughout the nucleus in Cizl KO NPCs.

Approximate localizations of the Xist transcription site were determined for each Xist territory based on fluorescence intensity and density of the newly synthesized Xist RNA signal of WT mESCs. A variation of NNA was used to measure the distance of said approximate transcription site to all newly synthesized Xist molecules and to all pre-synthesized Xist molecules separately. In order to account for variability in Xist territory size, distances were normalized to the maximum distance measured for each territory, which was set to 1 . This was then used to characterize the spreading behavior of newly synthesized Xist RNA molecules by comparing distance distributions in relation to the transcription site over time. Here, the Xist territory was divided into 3 zones, with zone 1, 2 and 3 extending 0-50 \%, 50-75 \% and 75-100 $\%$ of the maximum distance from the transcription site respectively. Then, the proportion of newly synthesized or pre-synthesized Xist RNA molecules in each zone over time was quantified. This approach allowed for the time-resolved comparison of newly synthesized Xist RNA molecule and pre-synthesized Xist RNA molecule distributions during both expansion and steady state in WT mESCs. A rate of expansion could be calculated, since NNA distances were measured in 3D and the 3D volumes of the Xist territories were already known. On average, Xist territories had a size of $98.9 \mu \mathrm{m}^{3}$ in expansion, which can be set equal to $100 \%$ of the normalized volume used to determine Xist spreading previously. On average, newly synthesized Xist extends across $29.9 \%$ of this volume after 20 min and $35.2 \%$ after 60 min, meaning that there is an increase of $5.3 \%$ of the Xist expansion volume within $40 \mathrm{~min} .5 .3 \%$ of the average Xist territory volume of $98.9 \mu \mathrm{m}^{3}$ corresponds to $5.1 \mu \mathrm{m}^{3}$. Based on this, the expansion rate of newly synthesized Xist RNA can be approximated as $7.7 \mu \mathrm{m}^{3} \mathrm{~h}^{-1}$. Furthermore, the localizations of transcription sites could be used to assess their distribution during expansion as compared to steady state phase. Here, 3D coordinates of Xist transcription sites were normalized to Xist territory dimensions and Xist territories were divided into 3 zones to account for variability in 35 Xist territory size.

Dual-color control. In order to exclude that the results obtained by NNA are result from simultaneous labelling of Xist RNA molecules with BglG-Halo fusion proteins labelled with the two different HaloTag ligands, a dual color control was performed. A total of 6 coverslips with

$40 \quad$ WT mESCs were induced for $24 \mathrm{~h}$ with $1 \mu \mathrm{g} / \mathrm{mL}$ doxycycline, before being incubated with medium containing $50 \mathrm{nM}$ diAcFAM HaloTag ligand (488 nm, Promega), $50 \mathrm{nM}$ JF-585 HaloTag ligand and $1 \mu \mathrm{g} / \mathrm{mL}$ doxycycline for $45 \mathrm{~min}$. Then, coverslips were washed with medium containing $1 \mu \mathrm{g} / \mathrm{mL}$ doxycycline for $15 \mathrm{~min}$, followed by a wash with PBS and preparation for imaging as described previously. 
Dox washout experiment. In order to assess the turnover on chromatin of Xist RNA when Xist transcription is reduced, a washout of doxycycline was performed. Here, 10 coverslips with cells were sequentially stained with two different HaloTag ligands. WT mESCs were induced for $1.5 \mathrm{~h}$ with $1 \mu \mathrm{g} / \mathrm{mL}$ doxycycline. Cells were then incubated with medium containing $50 \mathrm{nM}$ diAcFAM HaloTag ligand (488 nm, Promega) but without doxycycline for $45 \mathrm{~min}$ to label presynthesized Xist RNA molecules, before washing just with medium for $15 \mathrm{~min}$. Next, the different coverslips were incubated with $50 \mathrm{nM}$ JF-585 HaloTag ligand but without doxycycline for $60,80,100,120,140,160,180,200$ and 220 min respectively to label newly synthesized Xist RNA molecules, while one coverslip was not stained with the second HaloTag ligand and served as the 0 min time point. Coverslips were washed with PBS and samples were prepared for imaging as described previously. Induction and staining times with the first HaloTag ligand were staggered, such that all coverslips could be fixed at the same time despite the different staining times with the second HaloTag ligand. Successful reduction of Xist transcription was determined by comparison of the newly synthesized Xist RNA molecule count determined for the doxycycline washout experiment to that determined for WT mESCs during expansion.

\section{SLAM-seq}

Sample preparation. SLAM-seq of WT cells, as well as the corresponding parental cell line with untagged Xist, was performed using the SLAMseq Kinetics Kit, Catabolic Kinetics Module (Cat. No. 062.24, Lexogen). Cells were grown in gelatin-coated 6-well plates after pre-plating to discard feeder cells, with 6 wells needed for each experimental replica. When reaching 60-70 \% confluency, cells were induced with $1 \mu \mathrm{g} / \mathrm{mL}$ doxycycline for $17.5-20 \mathrm{~h}$ depending on the length of the subsequent washout times. Then, transcribed RNA was labelled with 4SU by incubation with medium containing $500 \mu \mathrm{M} 4 \mathrm{SU}$ (Lexogen) and $1 \mu \mathrm{g} / \mathrm{mL}$ doxycycline for $4 \mathrm{~h}$. Next, 4SU was withdrawn by washout for all samples except the 0 min sample. Different samples were washed with medium containing $1 \mu \mathrm{g} / \mathrm{mL}$ doxycycline and $50 \mathrm{mM}$ uridine (in excess, Lexogen) for 30, 60, 90, 120 and 150 min respectively. Induction, 4SU labelling and withdrawal times were staggered, such that all samples could be harvested at the same time despite the different washout times. After cells were collected by centrifugation at 1,500 $\mathrm{g}$ for 5 min in PBS, nuclear extracts were obtained as follows: Cells were washed again with PBS and resuspended in 10 volumes buffer A (10 mM HEPES pH 7.9, $1.5 \mathrm{mM} \mathrm{MgCl} 2,10 \mathrm{mM} \mathrm{KCl}, 0.5$ $\mathrm{mM}$ DTT and complete protease inhibitors in RNase free water). Subsequently cells were incubated on ice for 10 min and recovered by centrifugation, followed by resuspension in 3 volumes buffer A with $0.1 \% \mathrm{NP}-40$ for $10 \mathrm{~min}$. Nuclei were recovered by centrifugation at and TRIzol/chloroform RNA extraction was performed using the SLAMseq Kinetics Kit (Lexogen). Then, samples were treated with Iodoacetamide to modify the 4-thiol group of S4U-containing nucleotides via the addition of a carboxyamidomethyl group using the SLAMseq Kinetics Kit (Lexogen). The RNA was precipitated and washed again, before being resuspended in nuclease free water. $1 \mathrm{ng}$ RNA of each sample were run on the bioanalyzer to determine the exact RNA 40 concentration and RNA integrity of all samples. Based on this, $1 \mu \mathrm{g}$ RNA of each sample was then taken forward for library preparation using the Illumina TruSeq stranded total RNA kit (RS122-2301). Quantification of the libraries was performed by qPCR using KAPA Library Quantification DNA standards (Kapa Biosystems, KK4903). Finally, the libraries were pooled and $2 \times 81$ paired-end sequencing was performed using Illumina NextSeq500 (FC-404-2002). 
Data analysis. Estimation of nuclear RNA half-life was performed using GRAND-SLAM (요). Briefly, the paired-end sequencing reads were mapped to mouse genome mm10 by STAR (v2.5.2b) (39) with the key parameters (--outFilterMultimapNmax 1 --outFilterMismatchNmax 999 --alignEndsType EndToEnd). Given that T to C conversion is the signature of SLAMseq, the

$\mathrm{T}$ to $\mathrm{C}$ conversion rate was calculated as $4 \mathrm{SU}$ incorporation and the average of all the rest of the conversions was calculated as background due to errors from sequencing or library preparation. The $\mathrm{T}$ to $\mathrm{C}$ conversion rate and background rate were calculated accordingly for each sample. The nuclear RNA decay was assumed to follow an exponential model, so the T2C conversion rate (or T2C conversion rate-corresponding background rate) was fitted to the exponential model to estimate the RNA's nuclear half-life. In addition, the sample (dox-treated A11B2 cells, ChrRNA-seq) (27) without 4SU incorporation was used to estimate the background mutation rate for all 12 potential mismatches. Half-life of Xist RNA and another nuclear lncRNA Pvt1 were plotted.

\section{ChrRNA-seq}

Sample preparation. For ChrRNA-seq experiments, cells were grown in gelatin-coated T25 flasks with feeder cells. When confluent, cells were pre-plated for $40 \mathrm{~min}$ twice to discard the feeder cells, and expanded to gelatin-coated $15 \mathrm{~cm}$ dishes. Before chromatin RNA extraction, cells were induced for $3 \mathrm{~h}$ or $24 \mathrm{~h}$ with $1 \mu \mathrm{g} / \mathrm{mL}$ doxycycline for expansion and steady state respectively. A control sample comprising cells without addition of doxycycline was included with the analysis of each cell line. Chromatin RNA for each sequencing replica was extracted from one confluent $15 \mathrm{~cm}$ dish of cells. Cells were harvested and recovered by centrifugation at $1,000 \mathrm{rpm}$ for $3 \mathrm{~min}$ at room temperature, before being snap frozen on dry ice. Next, pellets were resuspended in RLB (10 mM Tris pH 7.5, $10 \mathrm{mM} \mathrm{KCl,} 1.5 \mathrm{mM} \mathrm{MgCl}_{2}$, and $\left.0.1 \% \mathrm{NP} 40\right)$ and incubated on ice for 5 min to lyse the cells. Nuclei were purified by centrifugation through a sucrose cushion ( $24 \%$ sucrose in RLB) at 2,800 $\mathrm{g}$ for $10 \mathrm{~min}$ at $4{ }^{\circ} \mathrm{C}$. The pellets were resuspended in NUN1 (20 mM Tris $\mathrm{pH} 7.5,75 \mathrm{mM} \mathrm{NaCl}, 0.5 \mathrm{mM}$ EDTA, $50 \%$ glycerol), and subsequently lysed with NUN2 (20 mM HEPES pH 7.9, $300 \mathrm{mM} \mathrm{NaCl}, 7.5 \mathrm{mM} \mathrm{MgCl} 2,0.2 \mathrm{mM}$ EDTA, $1 \mathrm{M}$ urea). Samples were incubated for $15 \mathrm{~min}$ on ice, vortexing occasionally, before being centrifuged at $2,800 \mathrm{~g}$ for $10 \mathrm{~min}$ at $4{ }^{\circ} \mathrm{C}$ to isolate the insoluble chromatin fraction. The pellets were resuspended in TRIzol and homogenized by passing multiple times through a 23 gauge needle. Finally, chromatin-associated RNA was purified through standard TRIzol/chloroform extraction followed by isopropanol precipitation. Samples were treated with Turbo DNase and the RNA was purified by RNeasy column cleanup (Qiagen). $100 \mathrm{ng}-1 \mu \mathrm{g}$ RNA of each sample were taken forward for library preparation using the Illumina TruSeq stranded total RNA kit (RS-122-2301). Quantification of the libraries was performed by qPCR with KAPA Library Quantification DNA standards (Kapa Biosystems, KK4903). Finally, the libraries were pooled and $2 \times 81$ paired-end sequencing was performed using Illumina NextSeq500 (FC-404-2002).

Data analysis. The analysis strategy that was used for ChrRNA-seq has been described in detail (27). In brief, raw fastq files of read pairs were mapped to an rRNA build by bowtie2 (v2.3.2), while rRNA-mapped reads were discarded. Remaining unmapped reads were aligned to the "Nmasked" genome (from mm10 coordinates) with STAR (v2.4.2a) using parameters "outFilterMultimapNmax 1 -outFilterMismatchNmax 4 -alignEndsType EndToEnd". Unique alignments were retained for further analysis. 23,005,850 SNPs between Cast and 129S genomes 
identified previously ( $\underline{40})$, were used for allelic split. These were used to split the alignment into distinct alleles (Cast and 129S) with the help of SNPsplit (v0.2.0; Babraham Institute, Cambridge, UK). The allelic read numbers were counted using the program featureCounts (-t transcript -g gene_id -s 2) (니), while the alignments were sorted by Samtools ( $\underline{42})$. For bi-allelic analysis, counts were normalized to one million mapped read pairs using the edgeR $\mathrm{R}$ package. Genes with a minimum of 10 SNP-covering reads across all the samples were further taken to calculate the allelic ratio of $\mathrm{Xi} /(\mathrm{Xi}+\mathrm{Xa})$. Here, $\mathrm{Xi}$ and $\mathrm{Xa}$ indicate the inactive and active allele, respectively. Xist mediated gene silencing during expansion and steady state was determined by the difference in the aforementioned allelic ratios between uninduced and doxycycline induced samples.

\section{ChIP-seq}

ES tissue culture. Biological replicate clones for $\mathrm{SPEN}^{\triangle \mathrm{RRM}}$ and SPEN ${ }^{\mathrm{SPOCmut}}$ were derived from iXist-Chr X cells. ES cells cultured on feeders were pre-plated for $30 \mathrm{~min}$, then plated on $15 \mathrm{~cm}$ dishes. Xist was induced by addition of $1 \mu \mathrm{g} / \mathrm{mL}$ doxycycline to growth media $3 \mathrm{~h}$ or $24 \mathrm{~h}$ prior to harvesting cells. Whereas all samples for the $3 \mathrm{~h}$ experiment were processed in parallel on the same day, for the $24 \mathrm{~h}$ experiment the SPEN ${ }^{\triangle R R M}$ lines, SPEN ${ }^{\text {SPOCmut }}$ cell lines, and each of the three replicates of iXist-Chr X (WT) cells were processed on separate occasions.

Native ChIP-seq. H2AK119ub1 native ChIP-seq was performed for iXist-Chr X, SPEN ${ }^{\triangle \mathrm{RRM}}$ and SPEN $^{\text {SPOCmut }}$ ES cell lines largely as previously described (27) using buffers supplemented with $10 \mathrm{mM}$ of the deubiquitinase inhibitor N-ethylmaleimide (Sigma, E3876-5G) throughout. Briefly, 50x10 ${ }^{6}$ ES cells were lysed in RSB (10 mM Tris pH 8, $10 \mathrm{mM} \mathrm{NaCl}, 3 \mathrm{mM} \mathrm{MgCl}, 0.1$ $\%$ NP40) for $5 \mathrm{~min}$ on ice with gentle inversion. Nuclei were resuspended in $1 \mathrm{~mL}$ of $\mathrm{RSB}+0.25$ M sucrose $+3 \mathrm{mM} \mathrm{CaCl}_{2}$, treated with $200 \mathrm{U}$ of MNase (Fermentas) for $5 \mathrm{~min}$ at $37^{\circ} \mathrm{C}$, quenched with $4 \mu \mathrm{L}$ of $1 \mathrm{M}$ EDTA, then centrifuged at 5,000 rpm for $5 \mathrm{~min}$. The supernatant was transferred to a fresh tube as fraction $\mathrm{S} 1$. The chromatin pellet was incubated for $1 \mathrm{~h}$ in $300 \mu \mathrm{L}$ of nucleosome release buffer (10 mM Tris pH 7.5, $10 \mathrm{mM} \mathrm{NaCl}, 0.2 \mathrm{mM}$ EDTA), carefully passed five times through a $27 \mathrm{G}$ needle and then centrifuged at $5,000 \mathrm{rpm}$ for $5 \mathrm{~min}$. The supernatant from this S2 fraction was combined with S1 as soluble chromatin extract. For each ChIP reaction, $100 \mu \mathrm{L}$ of chromatin was diluted in Native ChIP incubation buffer (10 mM Tris pH 7.5, $70 \mathrm{mM} \mathrm{NaCl}, 2 \mathrm{mM} \mathrm{MgCl} 2,2 \mathrm{mM}$ EDTA, $0.1 \%$ Triton) to $1 \mathrm{~mL}$ and incubated with $4 \mu \mathrm{L}$ H2AK119ub1 Ab (Cell Signalling Technology, \#8240) overnight at $4{ }^{\circ} \mathrm{C}$. Samples were incubated for $1 \mathrm{~h}$ with $40 \mu \mathrm{L}$ protein A agarose beads pre-blocked in Native ChIP incubation buffer with $1 \mathrm{mg} / \mathrm{mL}$ BSA and $1 \mathrm{mg} / \mathrm{mL}$ yeast tRNA, then washed for a total of four times in Native ChIP wash buffer (20 mM Tris pH 7.5, 2 mM EDTA, $125 \mathrm{mM} \mathrm{NaCl}, 0.1 \%$ Triton) and once in TE. The DNA was eluted with $1 \% \mathrm{SDS}$ and $100 \mathrm{mM} \mathrm{NaHCO}_{3}$, and was purified using the ChIP DNA Clean and Concentrator kit (Zymo Research). 50 ng of ChIP DNA was used for library prep using the NEBNext Ultra II DNA Library Prep Kit with NEBNext Single indices

40 (E7645), and then quantified using a Bioanalyzer 2100 (Agilent) and a Qubit fluorometer (Invitrogen). The libraries were pooled and $2 \times 81$ paired-end sequencing was performed using Illumina NextSeq500 (FC-404-2002).

Native ChIP-seq data analysis. Raw fastq read pairs were mapped to the "N-masked" mm10 genome by bowtie 2 (v2.2.6) using parameters "--very-sensitive --no-discordant --no-mixed -X 2000”. Alignment files were subsequently filtered to remove unmapped read pairs and PCR 
duplicates (picard-tools MarkDuplicates). For allelic analysis, we made use of SNPs between Cast and 129S genomes and employed SNPsplit (v0.2.0; Babraham Institute, Cambridge, UK) to split 55-60\% of filtered alignments into distinct alleles (Cast and 129S) using the parameter "-paired". Each alignment file was then processed into bedGraph format by genomeCoverageBed (BEDtools; $\underline{43}$ ) and normalized to the total library size of the sample. The custom script ExtractInfoFrombedGraph_AtBed.py (https://github.com/guifengwei) was used to extract values of H2AK119ub1 enrichment for $250 \mathrm{~kb}$ windows spanning the whole Chr X (Fig. 5) or the 103.5 $\mathrm{Mb}$ region of Chr X proximal to Xist (fig. S10). Gain of H2AK119ub1 upon Xist expression was calculated by subtraction of Uninduced from $24 \mathrm{~h}$ or $3 \mathrm{~h}$ induced samples (Dox - NoDox). Line plots were generated in $\mathrm{R}$ from replicates averaged for each mutant (3x iXist-Chr $\mathrm{X}$ technical replicates, 2x SPEN ${ }^{\triangle R R M}$ clones, $2 x \operatorname{SPEN}^{\text {SPOCmut }}$ clones).

Western blot. For CIZ1 Western blot experiments, the candidate KO clones, and WT cells serving as control, were grown in gelatin-coated T25 flasks each with feeder cells. When confluent, cells were pre-plated for 40 min twice to discard the feeder cells, and subsequently plated in a well of a gelatin-coated 6-well plate each. When confluent, cells were washed with PBS and detached using TrypLE Express (Thermo Fisher Scientific). Cells were washed and recovered by centrifugation, before $3 \times 10^{6}$ cells of each clone were dissolved in $200 \mu \mathrm{L} 2 \mathrm{x}$ SMASH buffer (33 mM Tris-HCl (pH 6.8), $11 \%$ Glycerol, 40 mg/mL SDS, $200 \mu \mathrm{g} / \mathrm{mL}$ bromophenol blue and $10 \% \beta$-mercaptoethanol in nuclease free water). Samples were left shaking for $20 \mathrm{~min}$, and then snap frozen on dry ice and thawed once. Samples were then separated by SDS polyacrylamide gel electrophoresis (8\% separating gel and $5 \%$ stacking gel) at $80 \mathrm{~V}$ for $15 \mathrm{~min}$, and then at $180 \mathrm{~V}$ for another $70 \mathrm{~min}$. Next, samples were transferred onto a PVDF membrane by semi-dry transfer at $15 \mathrm{~V}$ for $1 \mathrm{~h}$. The membrane was blocked by incubation with $10 \mathrm{~mL}$ PBS, $0.1 \%$ Tween (PBST) with $5 \% \mathrm{w} / \mathrm{v}$ Marvel milk powder for $1 \mathrm{~h}$ at room temperature. The membrane was then incubated with the corresponding primary antibody (CIZ1, anti-rabbit, affinity purified, polyclonal (a kind gift from the Coverley lab, University of York); and tubulin, anti-rabbit, Cell Signaling, Cat. No 2144) diluted 1:1000 in PBST with 5\% w/v Marvel milk powder at $4{ }^{\circ} \mathrm{C}$ overnight. The membrane was washed 3 times in PBST with $5 \%$ w/v Marvel milk powder for 10 min each, before being incubated with secondary antibody conjugated to horseradish peroxidase (anti-rabbit, HRP linked, Amersham) diluted 1:1000 in PBST with $5 \% \mathrm{w} / \mathrm{v}$ Marvel milk powder for $1 \mathrm{~h}$. After washes with PBST with $5 \% \mathrm{w} / \mathrm{v}$ Marvel milk powder and finally with PBST followed by PBS only, bands were visualized using ECL (GE Healthcare) for antibody detection.

\section{Southern blot}

For Southern blot analysis of candidate $\mathrm{SPEN}^{\triangle \mathrm{RRM}}$ clones, cells were grown in gelatin-coated T25 flasks each with feeder cells. When confluent, cells were pre-plated for $40 \mathrm{~min}$ twice to discard the feeder cells, and subsequently plated in a well of a gelatin-coated 6-well plate each.

$40 \quad$ Cells were washed 3 times with PBS, before $1 \mathrm{~mL}$ lysis buffer $(10 \mathrm{mM} \mathrm{NaCl}, 10 \mathrm{mM}$ Tris $\mathrm{pH}$ 7.5, $10 \mathrm{mM}$ EDTA pH 8, $0.5 \%$ sarcosyl; filter sterilized; $1 \mathrm{mg} / \mathrm{mL}$ Proteinase $\mathrm{K}$ added fresh) was added directly to each well to lyse the cells completely. Lysates were incubated at $55^{\circ} \mathrm{C}$ shaking at $300 \mathrm{rpm}$ overnight. Standard phenol chloroform extraction of the DNA was carried out using MaXtract High Density tubes (Qiagen). DNA was precipitated with $\mathrm{NaCl}$ and $\mathrm{EtOH}$ and the DNA was recovered by were centrifugation. Next, an EcoRV restriction digest of the samples was performed and $5 \mu \mathrm{g}$ digested DNA each were run on a $1 \% \mathrm{EtBr}$ agarose gel for $\sim 4$ 
$\mathrm{h}$ at $50 \mathrm{~V}$. The gel was incubated with depurination solution $(0.125 \mathrm{M} \mathrm{HCl}$ in MiliQ water) and for $15 \mathrm{~min}$, with denaturation buffer $(0.5 \mathrm{M} \mathrm{NaOH}, 1.5 \mathrm{M} \mathrm{NaCl}$ in Milli-Q water) for 45 min and finally with neutralization buffer (0.5 M Tris, $1.5 \mathrm{M} \mathrm{NaCl}$ in Milli-Q water, $\mathrm{pH}$ 8) for $30 \mathrm{~min}$. After capillary transfer overnight to an Immobilon NY+ membrane (Millipore) for at least $18 \mathrm{~h}$, the membrane was air dried and UV crosslinked using the Stratalinker.

The membrane pre-hybridized with Dextran - SLS - SCC hybridization solution prewarmed to $65^{\circ} \mathrm{C}(83 \mathrm{mg} / \mathrm{mL}$ dextran sulfate, 5x SSC and $0.875 \% \mathrm{~N}$-lauryl sarcosine sodium salt solution in MilliQ water filtered through a $0.8 \mu \mathrm{M}$ membrane before addition of $48 \mu \mathrm{g} / \mathrm{mL}$ denatured sheared salmon sperm DNA just before use) for $1 \mathrm{~h}$ at $65^{\circ} \mathrm{C}$. The probe was prepared using the prime-H II kit (Stratagene) as follows from a $626 \mathrm{bp}$ fragment downstream of the sgRNA used for the SPEN ${ }^{\triangle R R M}$ in exon 12 (table S1). The probe was purified using a G50 Micro column (GE Healthcare), before being boiled for $5 \mathrm{~min}$ at $95^{\circ} \mathrm{C}$. The denatured probe was placed on ice for $1 \mathrm{~min}$, added to the hybridization mixture and membrane, and then hybridized overnight at $65-67^{\circ} \mathrm{C}$. The next day, the membrane was washed twice with low stringency at $65{ }^{\circ} \mathrm{C}$ for $15 \mathrm{~min}$ each. It was subsequently exposed in a Fuji cassette overnight, before it was scanned on a FLA-7000 (Fujifilm). Mutant bands were detectable at $2.64 \mathrm{~kb}$, while WT bands were detectable at $4 \mathrm{~kb}$.

\section{Statistical analysis}

For the comparison of two independent large datasets throughout the project, statistical significance was determined by conducting an unpaired two-sample Wilcoxon test using R. This statistical test determines whether it is equally likely that a randomly selected value from one dataset will be less than or greater than a randomly chosen value from another population, making it ideal to determine whether two large datasets have the same distribution. Hence, the unpaired two-sample Wilcoxon test was used as a non-parametric alternative to the unpaired ttest to determine statistical significance.

\section{References and Notes:}

1. J. A. Graves, Evolution of vertebrate sex chromosomes and dosage compensation. Nat. Rev. Genet. 17, 33-46 (2016).

2. I. Pinheiro, E. Heard, X chromosome inactivation: new players in the initiation of gene silencing. F1000Research 6, 344 (2017).

3. J. T. Lee, R. Jaenisch, Long-range cis effects of ectopic X-inactivation centres on a mouse autosome. Nature 386, 275-279 (1997).

4. A. Wutz, R. Jaenisch, A shift from reversible to irreversible $X$ inactivation is triggered during ES cell differentiation. Mol. Cell 5, 695-705 (2000).

5. S. M. Duthie, T. B. Nesterova, E. J. Formstone, A. M. Keohane, B. M. Turner, S. M. Zakian, N. Brockdorff, Xist RNA exhibits a banded localization on the inactive X chromosome and is excluded from autosomal material in cis. Hum. Mol. Genet. 8, 195-204 (1999).

6. C. M. Clemson, J. A. McNeil, H. F. Willard, J. B. Lawrence, XIST RNA paints the inactive $\mathrm{X}$ chromosome at interphase: evidence for a novel RNA involved in nuclear/chromosome structure. J. Cell Biol. 132, 259-275 (1996). 
7. Y. Hasegawa, N. Brockdorff, S. Kawano, K. Tsutui, S. Nakagawa, The matrix protein hnRNPU is required for chromosomal localization of Xist RNA. Dev. Cell 19, 469-476 (2010).

8. C. Chu, Q. C. Zhang, S. T. da Rocha, R. A. Flynn, M. Bharadwaj, J. M. Calabrese, T. Magnuson, E. Heard, H. Y. Chang, Systematic discovery of Xist RNA binding proteins. Cell 161, 404-416 (2015).

9. R. Ridings-Figueroa, E. R. Stewart, T. B. Nesterova, H. Coker, G. Pintacuda, J. Godwin, R. Wilson, A. Haslam, F. Lilley, R. Ruigrok, S. A. Bageghni, G. Albadrani, W. Mansfield, J.A. Roulson, N. Brockdorff, J. F. X. Ainscough, D. Coverley, The nuclear matrix protein CIZ1 facilitates localization of Xist RNA to the inactive X-chromosome territory. Genes Dev. 31, 876-888 (2017).

10. H. Sunwoo, D. Colognori, J. E. Froberg, Y. Jeon, J. T. Lee, Repeat E anchors Xist RNA to the inactive $\mathrm{X}$ chromosomal compartment through CDKN1A-interacting protein (CIZ1). Proc. Natl Acad. Sci. USA 114, 10 654-10 659 (2017).

11. D. Smeets, Y. Markaki, V. J. Schmid, F. Kraus, A. Tattermusch, A. Cerase, M. Sterr, S. Fiedler, J. Demmerle, J. Popken, H. Leonhardt, N. Brockdorff, T. Cremer, L. Schermelleh, M. Cremer, Three-dimensional super-resolution microscopy of the inactive X chromosome territory reveals a collapse of its active nuclear compartment harboring distinct Xist RNA foci. Epigenetics Chromatin 7, 8 (2014).

12. J. M. Engreitz, K. Sirokman, P. McDonel, A. Shishkin, C. Surka, P. Russell, S. R. Grossman, A. Y. Chow, M. Guttman, E. S. Lander, RNA-RNA interactions enable specific targeting of noncoding RNAs to nascent pre-mRNAs and chromatin sites. Cell 159, 188-199 (2014).

13. J. M. Engreitz, A. Pandya-Jones, P. McDonel, A. Shishkin, K. Sirokman, C. Surka, S. Kadri, J. Xing, A. Goren, E. S. Lander, K. Plath, M. Guttman, The Xist lncRNA exploits threedimensional genome architecture to spread across the X chromosome. Science 341, 1237973 (2013).

14. N. Brockdorff, Localized accumulation of Xist RNA in X chromosome inactivation. Open Biology 9, 190213 (2019).

15. K. Ng, N. Daigle, A. Bancaud, T. Ohhata, P. Humphreys, R. Walker, J. Ellenberg, A. Wutz, A system for imaging the regulatory noncoding Xist RNA in living mouse embryonic stem cells. Mol Biol Cell. 22, 2634-2645 (2011).

16. N. Ha, L. T. Lai, R. Chelliah, Y. Zhen, S. P. Yi Vanessa, S. K. Lai, H. Y. Li, A. Ludwig, S. Sandin, L. Chen, L. F. Zhang, Live-cell Imaging and functional dissection of Xist RNA reveal mechanisms of $X$ chromosome inactivation and reactivation. iScience 8, 1-14 (2018).

17. B. Moindrot, A. Cerase, H. Coker, O. Masui, A. Grijzenhout, G. Pintacuda, L. Schermelleh, T. B. Nesterova, N. Brockdorff, A pooled shRNA screen identifies Rbm15, Spen, and Wtap as factors required for Xist RNA-mediated silencing. Cell Rep. 12, 562-572 (2015).

18. Y. Markaki, J. G. Chong, C. Luong, S. Y.X. Tan, Y. Wang, E. C. Jacobson, D. Maestrini, I. Dror, B. A. Mistry, J. Schöneberg, A. Banerjee, M. Guttman, T. Chou, K. Plath, Xist-seeded nucleation sites form local concentration gradients of silencing proteins to inactivate the Xchromosome. bioRxiv (2020). doi: https://doi.org/10.1101/2020.11.22.393546 
19. V. A. Herzog, B. Reichholf, T. Neumann, P. Rescheneder, P. Bhat, T. R. Burkard, W. Wlotzka, A. von Haeseler, J. Zuber, S. L. Ameres, Thiol-linked alkylation of RNA to assess expression dynamics. Nature Methods 14, 1198-1204 (2017).

20. M. D. Simon, S. F. Pinter, R. Fang, K. Sarma, M. Rutenberg-Schoenberg, S. K. Bowman, B. A. Kesner, V. K. Maier, R. E. Kingston, J. T. Lee, High-resolution Xist binding maps reveal two-step spreading during X-chromosome inactivation. Nature 504, 465-469 (2013).

21. F. Kraus, E. Miron, J. Demmerle, T. Chitiashvili, A. Budco, Q. Alle, A. Matsuda, H. Leonhardt, L. Schermelleh, Y. Markaki, Quantitative 3D structured illumination microscopy of nuclear structures. Nat Protoc. 12, 1011-1028 (2017).

22. A. Monfort, G. Di Minin, A. Postlmayr, R. Freimann, F. Arieti, S. Thore, A. Wutz, Identification of Spen as a crucial factor for Xist function through forward genetic screening in haploid embryonic stem cells. Cell Rep. 12, 554-561 (2015).

23. Z. Lu, Q. C. Zhang, B. Lee, R. A. Flynn, M. A. Smith, J. T. Robinson, C. Davidovich, A. R. Gooding, K. J. Goodrich, J. S. Mattick, J. P. Mesirov, T. R. Cech, H. Y. Chang, RNA duplex map in living cells reveals higher-order transcriptome structure. Cell 165, 1267-1279 (2016).

24. C. A. McHugh, C.-K. Chen, A. Chow, C. F. Surka, C. Tran, P. McDonel, A. Pandya-Jones, M. Blanco, C. Burghard, A. Moradian, M. J. Sweredoski, A. A. Shishkin, J. Su, E. S. Lander, S. Hess, K. Plath, M. Guttman, The Xist lncRNA interacts directly with SHARP to silence transcription through HDAC3. Nature 521, 232-236 (2015).

25. J. J. Żylicz, A. Bousard, K. Žumer, F. Dossin, E. Mohammad, S. T. da Rocha, B. Schwalb, L. Syx, F. Dingli, D. Loew, P. Cramer, E. Heard, The implication of early chromatin changes in X chromosome inactivation. Cell 176, 182-197 e23 (2019).

26. F. Dossin, I. Pinheiro, J. J. Żylicz, J. Roensch, S. Collombet, A. Le Saux, T. Chelmicki, M. Attia, V. Kapoor, Y. Zhan, F. Dingli, D. Loew, T. Mercher, J. Dekker, E. Heard, SPEN integrates transcriptional and epigenetic control of X-inactivation. Nature 578, 455-460 (2020).

27. T. B. Nesterova, G. Wei, H. Coker, G. Pintacuda, J. S. Bowness, T. Zhang, M. Almeida, B. Bloechl, B. Moindrot, E. J. Carter, I. Alvarez Rodrigo, Q. Pan, Y. Bi, C.-X. Song, N. Brockdorff, Systematic allelic analysis defines the interplay of key pathways in X chromosome inactivation. Nat. Commun. 10, 3129 (2019).

28. A. Wutz, T. P. Rasmussen, R. Jaenisch, Chromosomal silencing and localization are mediated by different domains of Xist RNA. Nat Genet. 30, 167-174 (2002).

29. M. Ariyoshi, J. W. R. Schwabe, A conserved structural motif reveals the essential transcriptional repression function of Spen proteins and their role in developmental signalling. Genes \& Development 17, 1909-1920 (2003).

30. E. Miron, R. Oldenkamp, J. M. Brown, D. M. S. Pinto, C. S. Xu, A. R. Faria, H. A. Shaban, J. D. P. Rhodes, C. Innocent, S. de Ornellas, H. F. Hess, V. Buckle, L. Schermelleh, Chromatin arranges in chains of mesoscale domains with nanoscale functional topography independent of cohesin. Science Advances 6, eaba8811 (2020). 
31. G. V. Los, L. P. Encell, M. G. McDougall, D. D. Hartzell, N. Karassina, C. Zimprich, M. G. Wood, R. Learish, R. F. Ohana, M. Urh, D. Simpson, J. Mendez, K. Zimmerman, P. Otto, G. Vidugiris, J. Zhu, A. Darzins, D. H. Klaubert, R. F. Bulleit, K. V. Wood, HaloTag: A Novel Protein Labeling Technology for Cell Imaging and Protein Analysis. ACS Chemical Biology 3, 373-382 (2008).

32. F. Oswald, P. Rodriguez, B. D. Giaimo, Z. A. Antonello, L. Mira, G. Mittler, V. N. Thiel, K. J. Collins, N. Tabaja, W. Cizelsky, M. Rothe, S. J. Kühl, M. Kühl, F. Ferrante, K. Hein, R. A. Kovall, M. Dominguez, T. Borggrefe, A phospho-dependent mechanism involving NCoR and KMT2D controls a permissive chromatin state at Notch target genes. Nucleic Acids Research 44, 4703-4720 (2016).

33. L. Conti, S. M. Pollard, T. Gorba, E. Reitano, M. Toselli, G. Biella, Y. Sun, S. Sanzone, Q.L. Ying, E. Cattaneo, A. Smith, Niche-Independent Symmetrical Self-Renewal of a Mammalian Tissue Stem Cell. PLoS Biol. 3, e283 (2005).

34. E. Splinter, E. de Wit, E. P. Nora, P. Klous, H. J. van de Werken, Y. Zhu, L. J. Kaaij, W. van Ijcken, J. Gribnau, E. Heard, W. de Laat, The inactive X chromosome adopts a unique three-dimensional conformation that is dependent on Xist RNA. Genes \& Development 25,1371-1383 (2011).

35. G. Ball, J. Demmerle, R. Kaufmann, I. Davis, I. M. Dobbie, L. Schermelleh, SIMcheck: a toolbox for successful super-resolution Structured Illumination Microscopy. Sci Rep 5, 15915 (2015).

36. L. Rodermund, H. Coker, R. Oldenkamp, G. Wei, J. Bowness, B. Rajkumar, T. Nesterova, D. Pinto, L. Schermelleh, N. Brockdorff, makefile and scripts for: Time-resolved structured illumination microscopy reveals key principles of Xist RNA spreading. Zenodo (2021). https://doi.org/10.5281/zenodo.4725861

37. A. Matsuda, L. Schermelleh, Y. Hirano, T. Haraguchi, Y. Hiraoka, Accurate and fiducialmarker-free correction for three-dimensional chromatic shift in biological fluorescence microscopy. Sci Rep. 8, 7583 (2018).

38. C. Jurges, L. Dolken, F. Erhard, Dissecting newly transcribed and old RNA using GRANDSLAM. Bioinformatics 34, i218-i226 (2018).

39. A. Dobin, C. A. Davis, F. Schlesinger, J. Drenkow, C. Zaleski, S. Jha, P. Batut, M. Chaisson, T. R. Gingeras, STAR: ultrafast universal RNA-seq aligner. Bioinformatics 29, 15-21 (2013).

40. G. Pintacuda, G. Wei, C. Roustan, B. A. Kirmizitas, N. Solcan, A. Cerase, A. Castello, S. Mohammed, B. Moindrot, T. B. Nesterova, N. Brockdorff, hnRNPK Recruits PCGF3/5PRC1 to the Xist RNA B-Repeat to Establish Polycomb-Mediated Chromosomal Silencing. Molecular Cell 68, 955-969 (2017).

41. Y. Liao, G. K. Smyth, W. Shi, featureCounts: an efficient general purpose program for assigning sequence reads to genomic features. Bioinformatics 30, 923-930 (2014).

42. H. Li, B. Handsaker, A. Wysoker, T. Fennell, J. Ruan, N. Homer, G. Marth, G. Abecasis, R. Durbin, The Sequence Alignment/Map format and SAMtools. Bioinformatics 25, 20782079 (2009). 
43. A. R. Quinlan, I. M. Hall, BEDTools: a flexible suite of utilities for comparing genomic features. Bioinformatics 26, 841-842 (2010).

Acknowledgments: We thank Amanda Williams for assistance with NGS sequencing; Luke Lavis for kindly providing a range of HaloTag ligands; David Sherratt, University of Oxford, and Alfredo Castello, University of Oxford, for valuable discussions. Funding: This work was funded by grants to L.R. from the Medical Research Council UK (MR/K501256/1) and grants to N.B. from the Wellcome Trust (103768). Imaging was performed at the Micron Oxford Advanced Bioimaging Unit funded by a Wellcome Trust Strategic Award (091911 and 107457/Z/15/Z). Author contributions: N.B., L.S., H.C. and L.R. conceived experiments, L.R., H.C., J.B., B.R. and T.N. carried out experiments, N.B., L.S., L.R. and H.C. and wrote manuscript, L.R. and R.O. performed image processing and analysis, G.W., R.O. and L.R. ran computational analysis, R.O. and D.P. provided computational scripts. Competing interests: Authors declare no competing interests. Data and materials availability: All data, parameters and scripts used are available for reproducing the results of this investigation. Raw and reconstructed 3D-SIM images were deposited to the Image Data Resource (https://idr.openmicroscopy.org) under accession number idr0110. The programs required to run all scripts for RNA-SPLIT image processing and analysis are: ImageJ (Fiji distribution with SIMcheck), R and Octave. Makefile and scripts are available on Zenodo (https://doi.org/10.5281/zenodo.4725861). All the high throughput sequencing data encompassing ChrRNA-seq, ChIP-seq, and SLAM-seq are deposited in GEO under GSE154568.

\section{Supplementary Materials:}

Supplementary Text

Figures S1-S12

Tables S1 and S2

References $(10,11,18)$

Movies S1 and S2 


\section{Figure legends:}

Fig. 1. Measuring Xist RNA behavior with RNA-SPLIT. (A) Schematic illustrating HaloTag labelling of Xist RNA in mESCs via the BglG/Bgl stem-loop system. (B) Combined Xist RNA FISH with HaloTag staining of BglG-Halo-Xist visualized by 3D-SIM and conventional widefield microscopy for comparison. DNA is counterstained with DAPI. Single cross-section of a 3D image stack displayed in lateral and orthogonal view. Scale bar: $1 \mu \mathrm{m}$. (C) Representative 3D-SIM images (z-projections) of Xist territories labelled by RNA FISH and HaloTag staining at different time points of Xist induction. Nuclear outlines are indicated in white. Scale bar: $2 \mu \mathrm{m}$. (D) Boxplots showing average number of focal Xist signals after Xist induction for different times determined from 3D-SIM analysis of Halo-BglG labelled Xist molecules. $\mathrm{n}=11$ cells/time point. (E) Schematic illustrating the RNA-SPLIT regimen and the parameters of Xist RNA behavior measured in this study. (F) Representative 3D-SIM image (single cross section) of Xist RNA-SPLIT showing newly synthesized (red) and pre-synthesized (cyan) Xist molecules during expansion. Arrows indicate examples of newly synthesized Xist molecules closely associating with pre-synthesized Xist molecules. Note, that in this inverted representation single pixels with similar cyan and red intensity display black. Scale bar: $1 \mu \mathrm{m}$.

Fig. 2. Xist RNA stability is defined by its chromatin environment and rate of transcription. (A) Schematic illustrating RNA-SPLIT regimen to assess Xist RNA turnover. (B) Representative 3D-SIM images (z-projections; inverted representation) of RNA-SPLIT experiment to assess Xist molecule turnover during expansion. Note pre-synthesized Xist molecules turnover more rapidly at the periphery of the territory. Scale bar: $2 \mu \mathrm{m}$. (C) Plot showing quantification of $\mathrm{Chr} \mathrm{X}$ and $\mathrm{Chr} 15$ Xist RNA turnover during expansion and steady state. $\mathrm{n}=20$ cells/time point. (D) Plots of SLAM-seq experiments conducted during steady state showing decrease of thymine to cytosine (T2C) conversions over time (left) and data for Xist RNA (BglG-Halo tagged) replicates fitted to exponential decay curves (right) from which $\mathrm{t}_{1 / 2}$ values are derived. The grey and red curves represent the raw $\mathrm{T} 2 \mathrm{C}$ conversion and backgroundcorrected conversion rates respectively. The red dashed line indicates $10 \%$ of original signal. (E) Representative 3D-SIM images (z-projections) of Xist RNA on Chr X during expansion. Scale bar: $2 \mu \mathrm{m}$. (F) Boxplots showing Xist RNA transcription over time during expansion and steady state phases. $\mathrm{n}=20$ cells/time point. (G) Plot showing effect of doxycycline washout on turnover of Xist molecules during expansion. Pre-synthesized Xist counts were normalized by setting the highest count for each sample to $100 \% . \mathrm{n}=20$ cells/time point.

Fig. 3. Localization behavior of Xist molecules. (A) Representative 3D-SIM images (single zsection) of RNA-SPLIT illustrating spread of Xist molecules in expansion phase. Approximated Xist transcription site is indicated with white cross. Scale bar: $2 \mu \mathrm{m}$. (B) Bar chart quantifying range of newly synthesized and pre-synthesized Xist molecules during expansion and steady state phases. Each signal was assigned to a zone as illustrated in schematic (right). $\mathrm{n}=40$ cells/time point. Significance determined by unpaired two-sample Wilcoxon test $(* * * p<0.0001)$. (C) Representative 3D-SIM image (single z-section) of RNA-SPLIT (left) and Xist RNA FISH combined with BglG HaloTag labelling (right) illustrating coupling of pre-synthesized and newly synthesized Xist molecules during expansion phase. Lower panels show examples of coupled Xist molecules. Single cross-sections. Selected couplets (arrows) are expanded in panels below. Scale bars: $2 \mu \mathrm{m}$ (main image) or $200 \mathrm{~nm}$ (lower panels). (D) Violin plots quantifying coupling of Xist molecules in expansion and steady state phases. $n=200$ cells/time point. 
Colocalization offset is defined using EdU control. Significance determined by unpaired twosample Wilcoxon test $(* * * \mathrm{p}<0.0001)$.

Fig. 4. Investigation of CIZ1 function in regulating Xist RNA behavior. (A) Schematic illustrating differentiation of WT and Cizl KO mESCs into NPCs. (B) Representative 3D-SIM images (z-projections) of Xist molecules in NPCs at day 10 of differentiation. Scale bar: $2 \mu \mathrm{m}$. (C) Boxplots representing density of Xist molecules in Cizl KO NPCs. $\mathrm{n}=40$ cells/time point. Significance determined using unpaired two-sample Wilcoxon test $(* * * p<0.0001)$. (D) Representative 3D-SIM images (single z-sections) of RNA SPLIT experiments for WT and Ciz1 KO NPCs after 20 days of differentiation showing coupling of pre-synthesized and newly synthesized Xist molecules. Selected couplets (arrows) are expanded in panels to the right. Scale bars: $2 \mu \mathrm{m}$ (main images), and $200 \mathrm{~nm}$ (expanded images). (E) Corresponding nearest neighbor analysis between Xist molecules in WT and Ciz1 KO NPCs. $\mathrm{n}=150$ cells/time point. Significance determined using unpaired two-sample Wilcoxon test $(* * * \mathrm{p}<0.0001)$.

Fig. 5. A role for SPEN in Xist RNA localization. (A) UCSC genome browser screenshot with ChrRNA-seq track confirming 38224 nucleotide deletion of sequences encoding the SPEN RRM region (top), with indication of nucleotide substitutions in the SPOC domain mutant confirmed by Sanger sequencing (bottom). (B) Representative 3D-SIM images (z-projections) showing Xist molecules within territories in WT and $\mathrm{SPEN}^{\triangle \mathrm{RRM}}$ mutant mESCs as indicated in both expansion and steady state phases. Scale bar: $2 \mu \mathrm{m}$. (C) Plots showing gain of H2AK119ub1 within $250 \mathrm{~kb}$ windows on chromosome $X$ determined by ChIP-seq analysis in SPEN ${ }^{\triangle R R M}$ cells (left) and SPEN $^{\text {SPOCmut }}$ cells (right) after $3 \mathrm{~h}$ (top) and $24 \mathrm{~h}$ (bottom) induction with doxycycline. The position of the Xist locus is indicated (arrow).

Fig. 6. SPEN modulates stability and coupling of Xist molecules. (A) Boxplots showing quantification of the density of Xist molecules in SPEN ${ }^{\triangle R R M}$ and SPEN ${ }^{\text {SPOCmut }}$ cells. $n=240$ cells/cell line. Significance determined using unpaired two-sample Wilcoxon test $(* * * \mathrm{p}<0.0001)$. (B) Boxplots showing Xist territory volume as proportion of nuclear volume in SPEN RRM deletion cells. $n=120$ cells/cell line. Significance determined using unpaired two-sample Wilcoxon test $(* * * p<0.0001)$. (C) Boxplots illustrating Xist RNA transcription in SPEN ${ }^{\triangle R R M}$ mESCs during expansion and steady state. $n=20$ cells/ time point. (D) Plot showing turnover of Xist molecules in mESCs during expansion and steady state as indicated. $n=20$ cells/time point. (E) Representative 3D-SIM images (single z-section) of RNA-SPLIT during steady state illustrating abrogation of coupling of Xist molecules in SPEN ${ }^{\triangle R R M} \mathrm{mESCs}$. Arrows indicate coupled Xist molecules. Insets showing corresponding z-projections. Scale bars: $2 \mu \mathrm{m}$. (F) Violin plots showing abrogated coupling of Xist molecules in SPEN ${ }^{\triangle R R M}$ mESCs. $n=200$ cells/time point. Significance determined using unpaired two-sample Wilcoxon test $\left({ }^{*} \mathrm{p}<0.05\right.$, $* * * \mathrm{p}<0.0001)$. 